\title{
Eye Movements in Monkeys with Local Dopamine Depletion in the Caudate Nucleus. I. Deficits in Spontaneous Saccades
}

\author{
Makoto Kato, ${ }^{\mathrm{a}}$ Nobuo Miyashita, ${ }^{\mathrm{D}}$ Okihide Hikosaka, Masaru Matsumura, Sadanari Usui, and Adriana Kori ${ }^{\mathrm{C}}$ \\ Laboratory of Neural Control, Department of Biological Control System, National Institute for Physiological Sciences, \\ Myodaiji, Okazaki 444, Japan
}

\begin{abstract}
The basal ganglia contribute to the suppression and initiation of saccadic eye movements through the inhibitory connection from the substantia nigra pars reticulata (SNr) to the superior colliculus. This mechanism consists of serial and parallel connections, which are mostly inhibitory and GABAergic. Dopamine is known to exert powerful modulatory effects on the basal ganglia function, but its nature and mechanism are still unclear, especially in relation to voluntary behavior.
\end{abstract}

The purpose of this series of investigation was to study the role of dopamine in the control of saccadic eye movements. We examined, in the monkey, whether and how the deficiency of the nigrostriatal dopaminergic innervation affects saccadic eye movements. The present article is focused on spontaneous saccades that the monkey made with no incentive to obtain reward; the next paper will describe task-specific saccades.

Using an osmotic minipump we infused 1-methyl-4-phenyl-1,2,3,6-tetrahydropyridine (MPTP) unilaterally into the head-body junction of the caudate nucleus of monkeys where presaccadic neurons were clustered. Tyrosine hydroxylase activity, visualized using an immunohistochemical method, decreased locally around the injection site with some effects extending into the ipsilateral putamen and locally in the ipsilateral substantia nigra.

Changes of eye movements started to appear 3-5 d after starting the infusion. Spontaneous saccades became less frequent. The area scanned by the saccades became narrower and shifted to the hemifield ipsilateral to the infusion site. The saccade amplitudes and peak velocities decreased; durations were prolonged. These effects were more prominent for saccades directed toward the side contralateral to the infusion site. These monkeys showed no obvious ske-

\footnotetext{
Received Mar. 14, 1994; revised July 20, 1994; accepted July 25, 1994.

We thank Prof. Toshihiro Maeda and Prof. Hiroshi Kimura for instruction in the tyrosine hydroxylase immunostaining method and Dr. Hisamasa Imai for instruction in the infusion method of MPTP. We also thank M. Nakanishi and $O$. Nagata for technical assistance. This study was supported by a grant (03251102) from the Japanese Ministry of Science, Education and Culture, and by Grant-inAid for Scientific Research on priority areas.

Correspondence should be addressed to Okihide Hikosaka, Department of Physiology, Juntendo University School of Medicine, 2-1-1 Hongo, Bunkyo-ku, Tokyo 113 , Japan.

aPresent address: Department of Cognitive Neuroscience, Osaka University Medical School, 2-2 Yamadaoka, Suita 565, Japan.

bPresent address: Department of Physiology, Juntendo University School of Medicine, 2-1-1 Hongo, Bunkyo-ku, Tokyo 113, Japan.

cPresent address: Department of Neurology, University Hospitals of Cleveland, 2074 Abington Road, Cleveland, OH 44106.

Copyright (C) 1995 Society for Neuroscience $0270-6474 / 95 / 150912-16 \$ 05.00 / 0$
}

letomotor symptoms. These results suggest that the local deprivation of the dopaminergic innervation in the caudate nucleus facilitates neuronal activity of the SNr leading to suppression of saccadic eye movements.

[Key words: monkey, MPTP, spontaneous eye movement, caudate nucleus, dopamine deficiency, parkinsonism, osmotic minipump]

The objective of our study was to understand the dopaminergic mechanism in the basal ganglia by examining oculomotor behaviors when the mechanism was lost. The basal ganglia system controls the initiation of saccadic eye movements via its efferent connection to the superior colliculus (Hikosaka and Wurtz, 1983b). The superior colliculus provides the brainstem reticular formation with burst signals which are then used for the generation of saccade (Sparks and Hartwich-Young, 1989). One of the most powerful inputs to the output neurons of the superior colliculus originates in the substantia nigra pars reticulata $(\mathrm{SNr})$, an output nucleus of the basal ganglia (Hikosaka and Wurtz, 1989). This connection is unique in that it is inhibitory and that it has high, sustained activity. Neurons in the SNr have high background spike activity, but decelerate or stop firing before saccadic eye movements (Hikosaka and Wurtz, 1983a), thus removing the inhibition of the superior colliculus (Hikosaka and Wurtz, 1983b). This disinhibition is induced by another inhibition at least partly originating in the caudate nucleus (Cd), one of the recipient structure of the basal ganglia (Hikosaka et al., 1989). In short, two serial inhibitory connections, both GABAergic, constitute the skeleton of the oculomotor control mechanism in the basal ganglia. In addition, a recent study in our laboratory (Matsumura et al., 1992) suggested that the subthalamic nucleus, with its excitatory connections to the $\mathrm{SNr}$, acts to suppress unnecessary saccades (when visual fixation is required) or to terminate a saccade. The basal ganglia could thus control saccadic eye movement in two ways: (1) by removing the nigrocollicular inhibition transiently and (2) by enhancing the inhibition.

However, the GABAergic mechanism in the basal ganglia would not work by itself. A variety of neurotransmitters and neuromodulators are crucial in expressing the integrative function of the basal ganglia (Graybiel, 1990). Dopamine is known to exert a powerful modulatory function. This is well demonstrated by the severe motor and behavioral deficits exhibited by parkinsonian patients. It is not straightforward, however, to understand the physiological mechanisms underlying the dopaminergic function. First, the dopaminergic system does not send signals out of the basal ganglia, unlike the GABAcrgic system. Dopaminergic neurons are concentrated in and around 
the substantia nigra pars compacta (SNc) and project mainly to the striatum (Parent et al., 1987). Any signals carried by the dopaminergic neurons must affect GABAergic neurons in the output structures (the internal segment of the globus pallidus and $\mathrm{SNr}$ ) to exert influence on other brain structures. It is thus reIIlarkable that the loss of dopaminergic ncurons scen in parkinsonian patients devastates their motor functions. A second difficulty arises from the ambiguity of the dopaminergic effects on single neurons. Dopamine may produce fast postsynaptic potentials (Kitai et al., 1976); it may modulate nondopaminergic synaptic transmissions (Bergstrom and Walters, 1984; Chiodo and Berger, 1986); or it may activate or suppress intracellular biochemical processes (Graybiel, 1990; Gerfen et al., 1991).

An animal model of dopamine deficiency, therefore, will provide an alternative to investigate the dopaminergic mechanism. For this type of approach to be successful, we need to have a good animal model and a good behavioral measure. Saccadic eye movement in MPTP (1-methyl-4-phenyl-1,2,3,6-tetrahydropyridine)-induced dopamine deficient animals should be ideal for this purpose. MP'P is known to destroy dopaminergic neurons in the $\mathrm{SNc}$, thus producing clinical symptoms quite similar to Parkinson's diseasc (Langston, 1985; German et al., 1988; Graham et al., 1990). As in Parkinson's disease the level of dopamine is decreased in the Cd of monkeys treated with MPTP (Mitchell et al., 1986; Elsworth et al., 1989; Schneider and Kovelowski, 1990).

To investigate the normal functions of the basal ganglia, the animals must be active and alert. However, this is very difficult for the MPTP-induced parkinsonian animals because their motor functions may well be devastated. Although abnormalities in saccadic eye movements have been reported after MPTP administration in humans and monkeys (Brooks et al., 1986; Hotson et al., 1986; Schultz et al., 1989a), it is sometimes difficult to dissociate movement deficits from general decrement of the arousal level. Such behavioral deterioration is inevitable when MPIP is administered intravenously or per-orally. Furthermore, MPTP also destroys dopaminergic neurons outside the SNc (A8 or A10) and norepinephrine and 5-HT neurons in the brainstem, albeit to a lesser extent, leading to significant decreases of these monoamines in cortical and brainstem areas (Schultz et al., 1989b; Pifl et al., 1991).

One solution to these problems is to destroy dopaminergic innervation within a small area in the basal ganglia. Recent studies have shown that the basal ganglia system is composed of different functional subdivisions. For example, the skeletomotor functions are largely represented in the putamen and the globus pallidus, while oculomotor and cognitive functions are represented in the $\mathrm{Cd}$ and the $\mathrm{SNr}$ (Alexander and Crutcher, 1990). We would then expect that a lesion in the Cd hinders oculomotor functions while sparing skeletomotor functions. Moreover, if a lesion is made unilaterally, only eye movements toward the contralateral side (with respect to the lesion) would be affected; ipsilateral eye movements could be used as a control.

We thought that osmotic minipump technique is suitable for local application of MPTP. It allows us to infuse a fixed amount of drug at a constant rate so that mechanical damages are minimized. Imai et al. (1988) successfully applied this technique for administration of MPTP. They infused MPTP unilaterally into the putamen of monkeys which subsequently developed a clear hemiparkinsonism; a local decrease of dopaminergic activity was then confirmed.

Using the same technique we infused MPTP into the $\mathrm{Cd}$ of the monkey which had been trained to perform a series of saccade tasks. As expected, these monkeys developed no clear skeletomotor symptoms but deficits were found in saccadic eye movements. The deficits were found when the monkeys were moving their eyes either spontaneously without a specific goal or while performing learned tasks. In this article we will describe the changes in spontaneous eye movements; the following companion article (Kori et al., 1994) will deal with task-specific saccades.

Preliminary reports of some of these data have appeared elsewhere (Kato et al., 1990; Miyashita et al., 1990; Usui et al., 1990).

\section{Materials and Methods}

\section{Experimental animals}

We used three male Japanese monkeys (Macaca fuscata): monkey RO $(8.1 \mathrm{~kg})$, monkey IG $(8.9 \mathrm{~kg})$, and monkey PE $(5.0 \mathrm{~kg})$. The monkey PE was the youngest and the monkey IG was the oldest, although their ages were unknown. Their spontaneous eye movements as well as task-specific saccades (Kori et al., 1994) were examined before and after a local infusion of MPTP into the caudate nucleus (Cd) on one side.

The monkeys were kept in individual primate cages in an air-conditioned room where food was always available. At each experimental session, they were brought to the experiment room. The monkeys were given restricted fluid during periods of training and recording. Their health conditions such as body weight and appetite were checked daily. Supplementary water and fruit were provided daily. All monkeys continued to be healthy, showing no apparent parkinsonian symptoms after MPTP administration (see Results).

\section{Surgical procedures}

MPTP was infused locally into the Cd using an osmotic minipump. The site of infusion was aimed at the head-body junction of the $\mathrm{Cd}$ where saccade-related cells are clustered (Hikosaka et al., 1989). The procedure was divided into 3 steps (Fig. 1).

Implantation of a head holder, a chamber, markers for magnetic resonance imaging, and an eye coil. Surgical procedures were conducted in an aseptic condition under general anesthesia. The anesthesia was introduced with ketamine $(5 \mathrm{mg} / \mathrm{kg}$ ) and xylazine $(2 \mathrm{mg} / \mathrm{kg})$ intramuscularly and then maintained with intravenous injection of pentobarbital sodium (initially $15 \mathrm{mg} / \mathrm{kg}$ and supplemented with $5 \mathrm{mg} / \mathrm{kg} / \mathrm{hour}$ ).

After exposing the skull, 20-30 acrylic screws were bolted onto it and fixed with a dental acrylic resin. The screws acted as anchors which fixed a head holder and a chamber (inner diameter, $18 \mathrm{~mm}$ ), both made of Delrin, to the skull. Use of metal in the headpiece was avoided to permit to get magnetic resonance images (MRIs). The chamber protected the drug-infusion guide tubes. The anteroposterior location of the chamber was determined based on the stereotaxic coordinate (A20A25); it was placed over the midline to cover the $\mathrm{Cd}$ on both sides. To correlate the stereotaxic coordinate and MRIs of the brain, we implanted several pieces of polyethylene tubes ( $3 \mathrm{~mm}$ o.d., $6 \mathrm{~mm}$ in length) vertically over the skull at the known stereotaxic coordinates (e.g., A25 and APO). The tubes when filled with liquid paraffine were clearly visible on the MRIs.

An eye coil was implanted over one eye for measurement of eye position using a search coil method (Matsumura et al., 1992). The animals received antibiotics (sodium ampicillin $25 \mathrm{mg} / \mathrm{kg}$ intramuscularly each day) after the operation.

MRIs. Based on brain MRIs (Hitachi Laboratory MRIS, 2.11 tesla) we determined the site for MPTP infusion. To obtain MRIs, we anesthetized the monkeys as for the surgical procedure. Their heads were fixed with the head holder in the cylindrical MRI probe. The stereotaxic coordinates of the infusion sites were determined on MRIs by comparing the location of the Cd with the locations of the MRI markers. The location of the chamber was also visible by filling it with liquid paraffin, and its relation to the $\mathrm{Cd}$ provided another measure for determining the infusion site. The stereotaxic coordinates for MPTP infusion were A20, L5 in the monkeys RO and PE and A25, L5 in the monkey IG. We also obtained MRIs after MPTP infusion to confirm the site of infusion and to see if there was structural changes due to the infusion.

Implantation of guide tubes for drug infusion. We then implanted two 


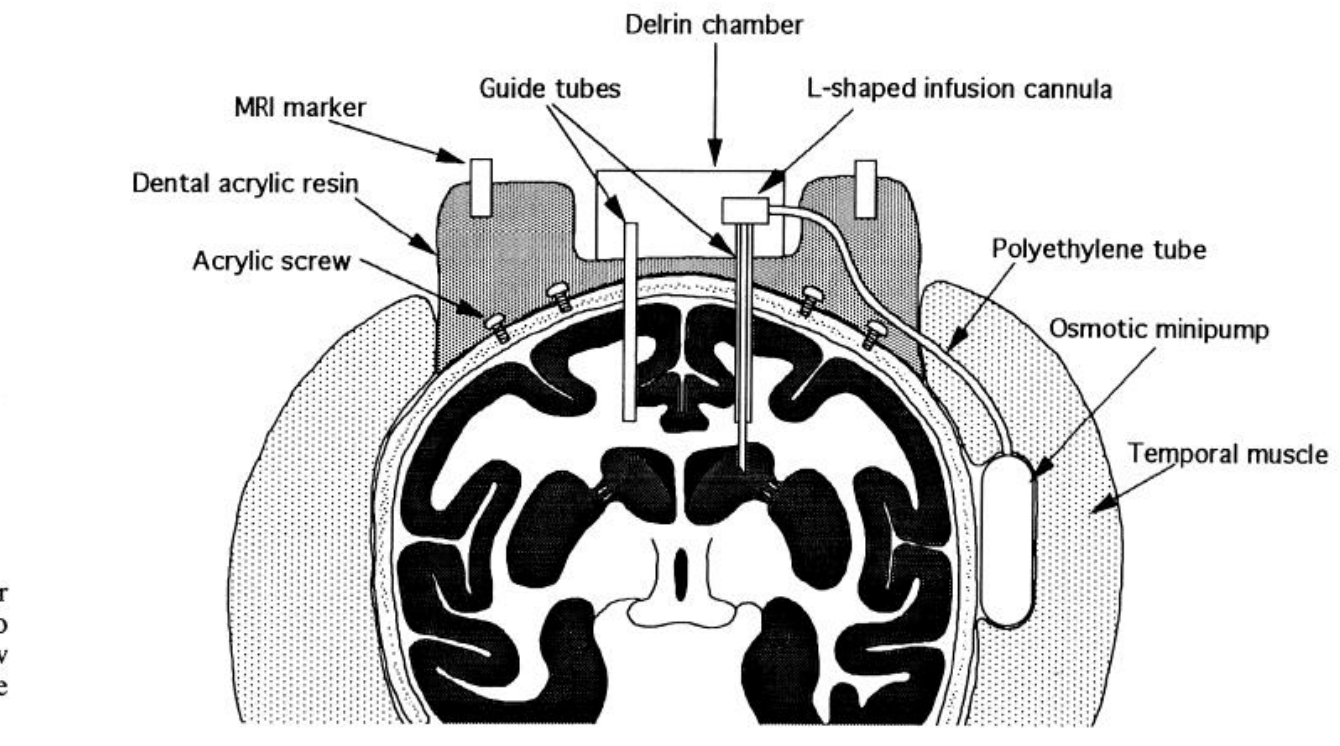

Figure 1. Placement of instruments for local, long-term infusion of MPTP into the unilateral $\mathrm{Cd}$ on the schematic view of a frontal section of the brain (see Materials and Methods).

guide tubes (Teflon tube, $0.8 \mathrm{~mm}$ o.d.) aiming at the $\mathrm{Cd}$ on both sides. This was performed under the anesthesia with ketamine and xylazine. This bilateral implantation allowed us to minimize the possible asymmetry of mechanical damages and to use one guide tube for MPTP infusion and the other for control saline infusion (see below). Their tips were located $5 \mathrm{~mm}$ above the target points. They were fixed to the skull using dental acrylic resin. Inside the guide tubes were placed stainless steel pipes $(0.5 \mathrm{~mm}$ o.d.) immersed in antibiotics ointment to prevent infection.

\section{Drug treatment}

MPTP (1-methyl-4-phenyl-1,2,3,6-tetrahydropyridine) hydrochloride (RBI Research Biochemicals Inc.) was dissolved in sterile saline (20 $\mathrm{mg} / \mathrm{ml}$ ) and infused in the Cd with an osmotic minipump (Alzet 2001 for the monkey RO and Alzet 2002 for the monkeys PE and IG; ejection rate, $1.0 \mu \mathrm{l} / \mathrm{hr}$ and $0.5 \mu \mathrm{l} / \mathrm{hr}$, respectively). Totally, $4 \mathrm{mg}$ MPTP was infused for each monkey. Implantation of the minipump was performed under the anesthesia with ketamine and xylazine. The minipump was placed in the medial side of the temporal muscle. Its outlet was connected to an L-shaped infusion cannula (stainless steel, $0.3 \mathrm{~mm}$ o.d.) through a polyethylene tube which was covered with a silicon tube and embedded in dental acrylic resin. The infusion cannula was inserted into the guide tube manually; its length was preadjusted with a stopper such that its tip reached the target point. One week after the estimated end of the delivery of MPTP, the pump was removed under the anesthesia with ketamine and xylazine.

For control experiments, we infused saline using the same osmotic minipump method in the same three monkeys. The amount of saline and the infusion period were made the same as MPTP infusion for each monkey. We employed three different schedules in terms of time and location of saline infusion. In the monkey RO, saline was injected 51 $\mathrm{d}$ after starting MPTP into the Cd on the opposite side, at the symmetric location. In the monkey PE, saline was injected before MPTP; $63 \mathrm{~d}$ thereafter MPTP was injected at the same location in the Cd. In the monkey IG, saline was injected simultaneously with MPTP on the opposite side, at the symmetric location.

In addition, we examined the effects of dopamine agonists on these monkeys when the deficits in eye movements reached a maximum level and became stable. We dissolved $1 \mathrm{mg}$ of apomorphine (Sigma Chemical Co.) in $1 \mathrm{ml}$ of sterile saline containing $0.05 \%$ ascorbic acid to avoid oxidation and injected intramuscularly to the monkeys. We compared eye movements between before and after apomorphine injection.

\section{Experimental procedures}

The daily experimental session was composed of (1) examination of spontaneous eye movements, and (2) examination of task-related saccades. The results of task-related saccades are presented in the following companion article (Kori et al., 1994). Eye movements were recorded using the magnetic search-coil technique (Robinson, 1963) (Enzanshi Kogyo MEL-20U).

The monkey sat in a primate chair with his head fixed in a sound attenuated room which could be made totally dark. In front of him was a tangent white screen ( $57 \mathrm{~cm}$ from his face) which was used to present visual targets in saccade tasks (see Kori et al., 1994). The untextured screen occupied the central $90^{\circ}\left( \pm 45^{\circ}\right.$, horizontal and vertical) of the monkey's view, which was fringed by the frames of the search coils.

Spontaneous eye movements were recorded in three conditions of background illumination; light ( $4 \mathrm{fcd}), \operatorname{dim}(0.02 \mathrm{fcd})$, and dark $(<0.001$ fcd; total darkness) conditions. For each condition, horizontal and vertical eye positions were recorded during a $3 \mathrm{~min}$ recording period. Eye position signals were sampled at a rate of $500 \mathrm{~Hz}$ and, after 12-bit AD conversion, were stored in the computer (NEC PC9801RA) for later off-line analysis. Eye position was calibrated using a saccade task (Kori et al., 1994).

The monkey's behavior was continuously monitored by an infrared camera, except for the dark condition in which the infrared light was also tuned off. The door to the experimental room was opened after each recording session to allow the monkey to hear voices of investigators and see their features, but no attempt was made to arouse the monkey during the $3 \mathrm{~min}$ recording period.

\section{Time schedule for examination}

We examined spontaneous eye movements before and after MPTP infusion. The acquisition of the pre-MPTP data was started after the monkey became used to be in the experimental room (while trained to perform saccade tasks). The pre-MPTP data were obtained for 7 consecutive days. The post-MPTP data were obtained daily or every other day for the first 2 weeks until deficits reached a maximum level; thereafter, the interval of the examination was lengthened until the recovery became stable.

\section{Off-line analyses of spontaneous eye movements}

The main part of the off-line analyses was to determine the time of saccade. Parameters used for the determination were eye velocity, acceleration, and duration. We judged that an eye movement (candidate of a saccade) occurred if velocity and acceleration exceeded threshold values $\left(30 \% \mathrm{sec}\right.$ and $90 \% \mathrm{sec}^{2}$, respectively). Since velocity and acceleration are actually two-dimensional vectors, we calculated the absolute values of these vectors at each sampling time and checked if they satisfied the above and following criteria for saccade detection. The eye movement was accepted as a saccade based on its velocity and duration. After the onset, the velocity must exceed $45 \% \mathrm{sec}$ and this suprathreshold velocity must be maintained for at least $10 \mathrm{msec}$. The total duration must be longer than $25 \mathrm{msec}$. The end of the eye movement was determined if the velocity became lower than $40 \% / \mathrm{sec}$. These threshold values were determined empirically by applying them to sample saccades. 

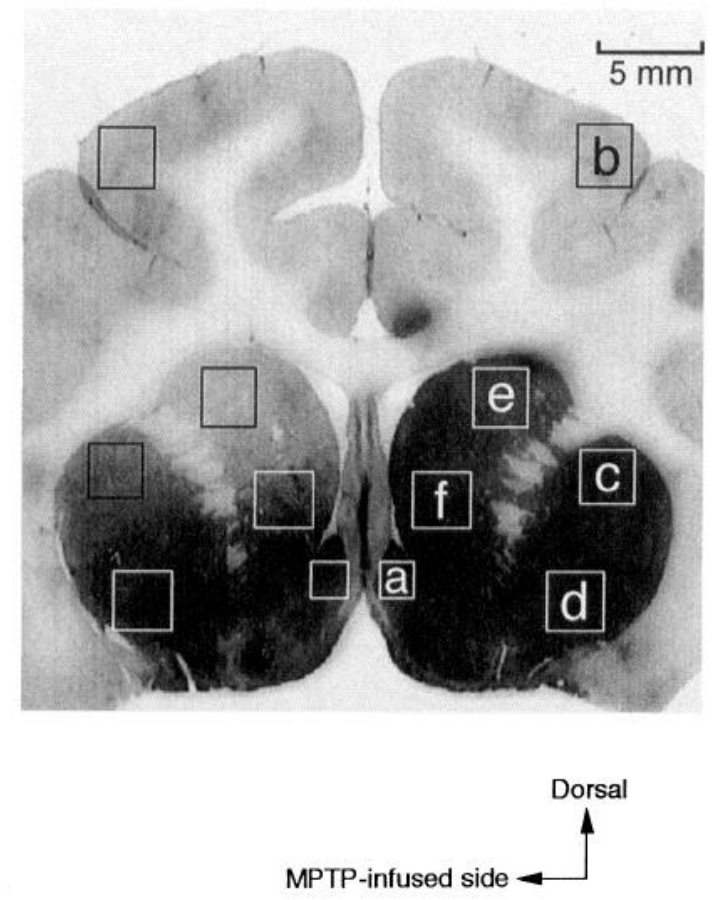
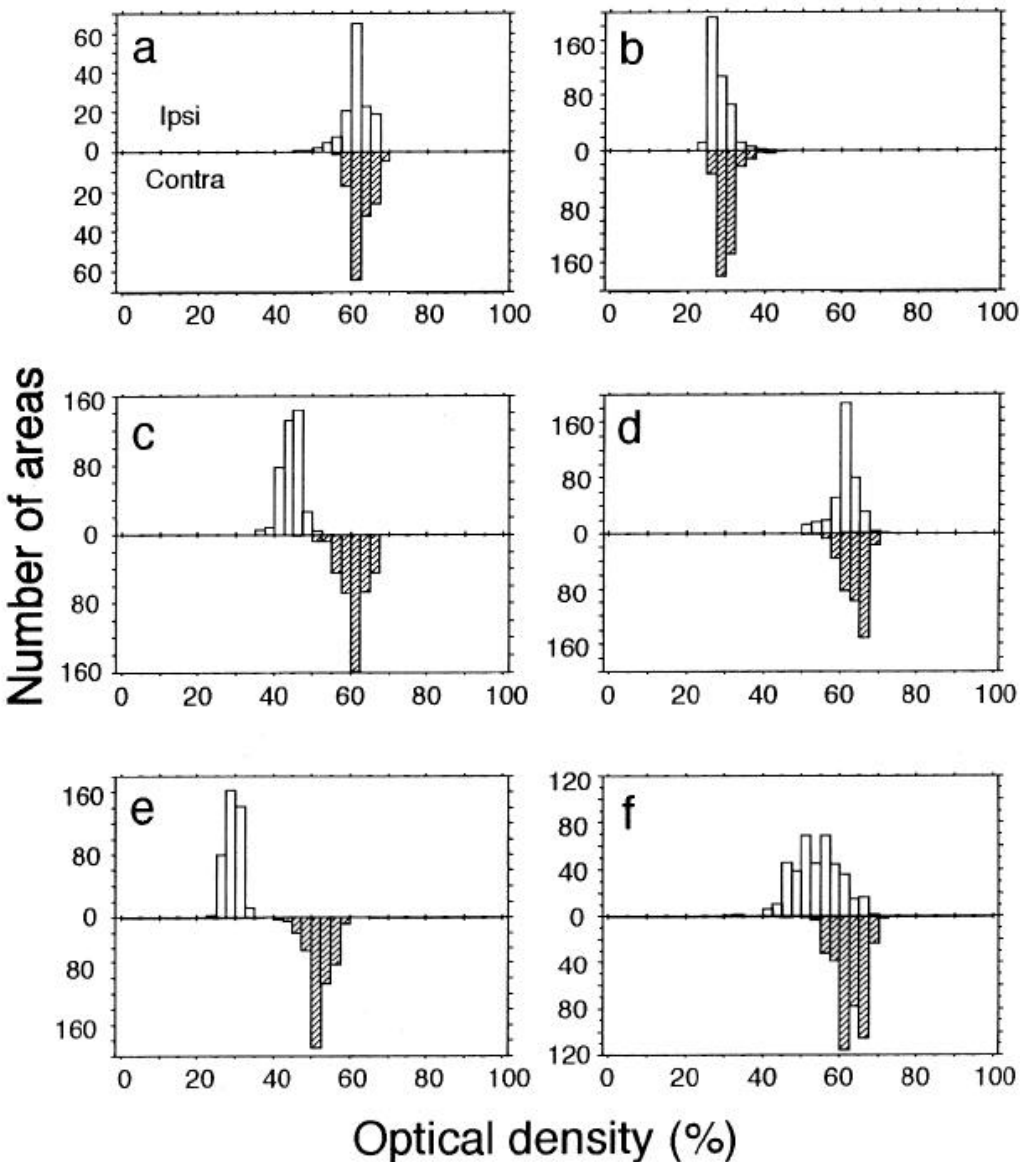

Figure 2. A scanner image showing tyrosine hydroxylase (TH) immunoreactivity in the frontal section (A25) at the level of the anterior putamen and the caudate head. MPTP was infused into the left Cd $5 \mathrm{~mm}$ posterior to this plane (see Materials and Methods). The data in Figures 2-5 were taken from the monkey RO. Open squares with lowercase characters $(a-f)$ indicate the areas of interest where optical density was measured. They were located symmetrically on both sides. Each area was divided into a few hundred small areas $(100 \times 100 \mu \mathrm{m})$ of which optical densities were measured and made into distribution histograms shown on the right side $(a-f)$. Open upward histograms (Ipsi) indicate the data from the infused side and hatched downward histograms (Contra) indicate those from the contralateral side. $a$, accumbens nucleus; $b$, dorsal bank of the dorsal arm of arcuate sulcus in the cerebral cortex; $c$, dorsal portion of the anterior putamen; $d$, ventral portion of the anterior putamen; $e$, dorsal portion of the caudate head; $f$, ventral portion of the caudate head.

For each saccade thus determined, we obtained several parameters: amplitude, peak velocity, duration, eye position at the beginning and end of the saccade, time of eye fixation preceding the saccade, and shift of eye position during the fixation period.

\section{Histology}

At the end of the series of experiments the animals were sacrificed under deep pentobarbital anesthesia $(50 \mathrm{mg} / \mathrm{kg}): 86,163$, and $94 \mathrm{~d}$ for the monkeys RO, PE, and IG, respectively, after the beginning of the MPTP infusion. They were then perfused transcardially with cooled saline and subsequently with a fixative ( $4 \%$ paraformaldehyde, $0.5 \%$ glutaraldehyde, and $0.2 \%$ picric acid in $0.01 \mathrm{M}, \mathrm{pH} 7.4$ phosphate buffer). The head was removed and fixed to the stereotaxic device. The skull was opened, and the brain was cut in the coronal plane into blocks of 12 $\mathrm{mm}$ thickness in the skull. Then the brain was removed and immersed for $2 \mathrm{~d}$ at $4^{\circ} \mathrm{C}$ in a postfixative solution ( $4 \%$ paraformaldehyde and $0.2 \%$ picric acid in $0.01 \mathrm{M}, \mathrm{pH} 7.4$ phosphate buffer), subsequently for 1 week at $4^{\circ} \mathrm{C}$ in $15 \%$ sucrose in $0.1 \mathrm{M}$ phosphate buffer. Frozen sections $(50$ $\mu \mathrm{m}$ thick) were made and stained with cresyl violet. Several sections including the areas of interest were stained with tyrosine hydroxylase (TH) immunostaining to evaluate the lesions of dopaminergic cells and fibers.

Procedure for TH immunostaining was the following. (1) Frec-floating sections were washed in phosphate-buffered saline containing $0.3 \%$ Triton X-100 (PBST) for a day at $4^{\circ} \mathrm{C}$, three times; (2) immersed in PBST containing $1 \% \mathrm{H}_{2} \mathrm{O}_{2}$ for $30 \mathrm{~min}$ at room temperature; (3) washed in PBST for $10 \mathrm{~min}$ at room temperature, three times; (4) incubated in
PBST with 3\% normal goat serum for $1 \mathrm{hr}$ at room temperature; (5) washed in PBST for $10 \mathrm{~min}$ at room temperature, three times; (6) incubated in PBST with a primary antibody to TH $(1: 250$; Eugene Tech, $1: 10000$; Incstar) for $3-5 \mathrm{~d}$ at $4^{\circ} \mathrm{C}$; (7) taken through the Vector $\mathrm{ABC}$ immunohistochemical method with diaminobenzidine as chromogen; and (8) mounted onto gelatine-coated slides, dehydrated, and coverslipped.

\section{Quantitative analysis of TH immunoreactivity}

We performed a quantitative analysis of densitometry of TH-immunoreactive fibers and cells for each animal on four frontal sections representing the rostral, middle and caudal striata, the substantia nigra pars reticulata, and the locus ceruleus. These sections were scanned by an image scanner (Epson GT-6000), and the optical density of selected square areas in the sections was measured. The pixel size of the scanner was $100 \times 100 \mu \mathrm{m}$, and its resolution of gradation was 8 bits. Evaluation of the differences was performed by comparing the mean of pixel data in the selected square areas between the control and the MPTP-infused sides.

\section{Results}

Regional difference of dopaminergic activity by unilateral MPTP infusion

Tyrosine hydroxylase ( $\mathrm{TH}$ ) immunostaining revealed, in all the three MPTP-infused monkeys, marked depletion of dopami- 

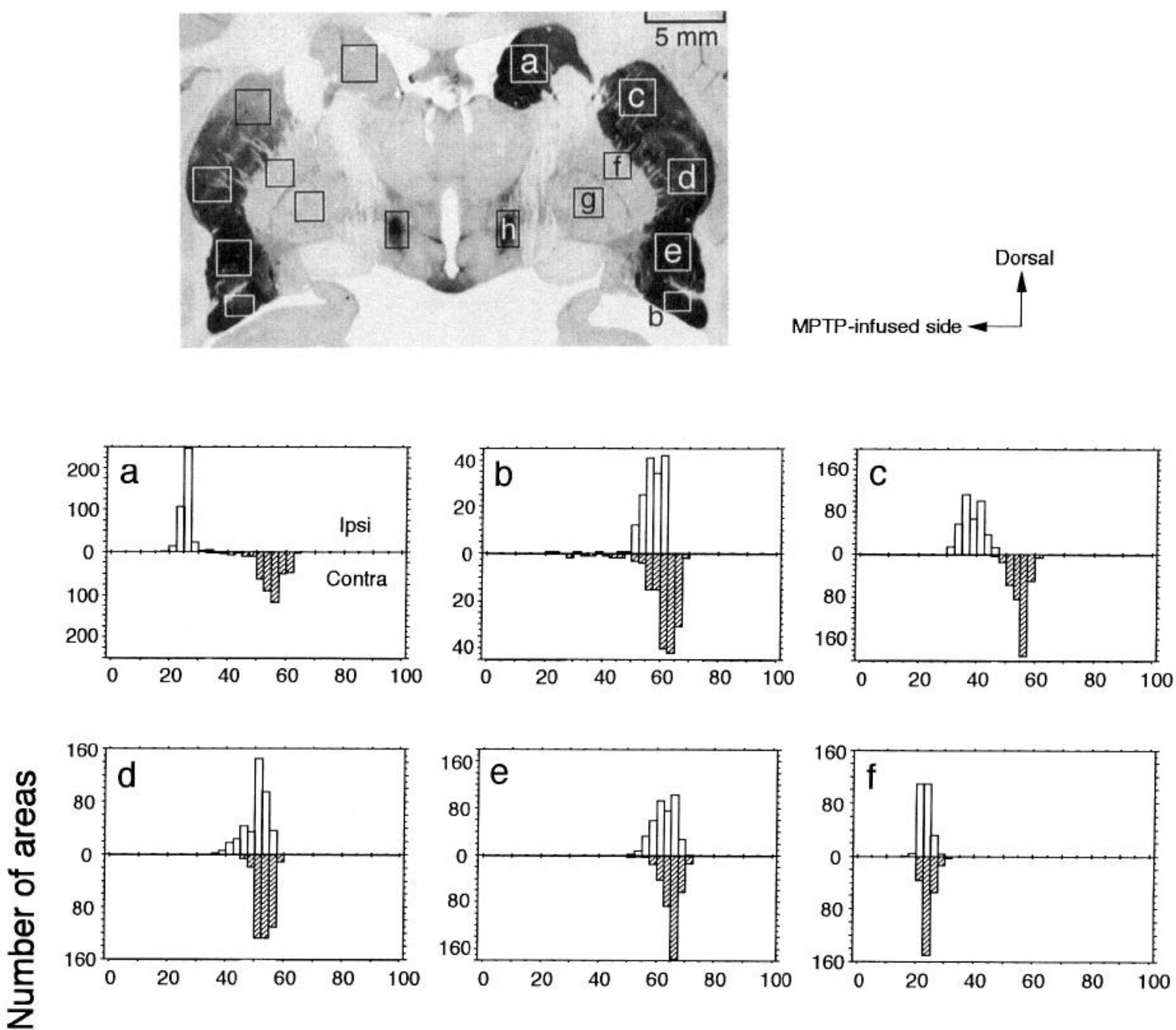

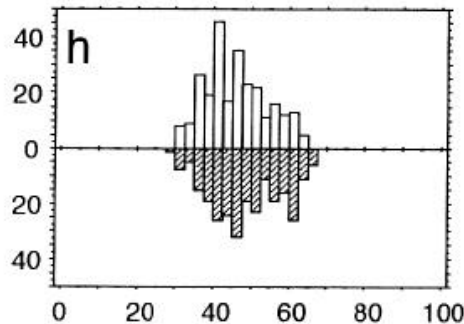

Optical density (\%)

Figure 3. A scanner image showing TH immunoreactivity in the frontal section (A17) near the level of the MPTP infusion. $a$, caudate body; $b$, ventral part of the caudate tail; $c$, dorsal portion of the putamen; $d$, middle portion of the putamen; $e$, ventral portion of the putamen; $f$, external pallidum; $g$, internal pallidum; h, medial forebrain bundle. Conventions are the same as Figure 2.

nergic fibers in the caudate nucleus (Cd) and the dorsal portion of the putamen around the infusion site in comparison with the control (contralateral) side.

To analyze the changes in TH activity quantitatively, we measured optical densities of $\mathrm{TH}$ reactive products and the visual inspection was confirmed. Figures 2-5 show the photographs of $\mathrm{TH}$-immunostained sections of the monkey RO, analyzed areas (squares in the sections), and the distribution histograms of optical density in each area. The areas in the striatum where optical density was markedly decreased were the head, body, and dorsal tail of the Cd (Figs. $2 e, f ; 3 a ; 4 a$ ), and the dorsal portion of the putamen (Figs. $2 c, 3 c, 4 c$ ).

In the ipsilateral substantia nigra pars compacta $(\mathrm{SNc})$ were found localized low-TH activity zones (Figs. 4, 5). Light microscopic inspection revealed loss of dopaminergic neurons in the central portion of the $\mathrm{SNc}$, suggesting that the infused MPTP was retrogradely transported to the cell soma (Imai et al., 1988). In contrast, there was no apparent difference in $\mathrm{TH}$ stained fibers between the ipsi- and contralateral sides in the prefrontal cortex, ventral-rostral portion of the putamen, and the nucleus accum- 

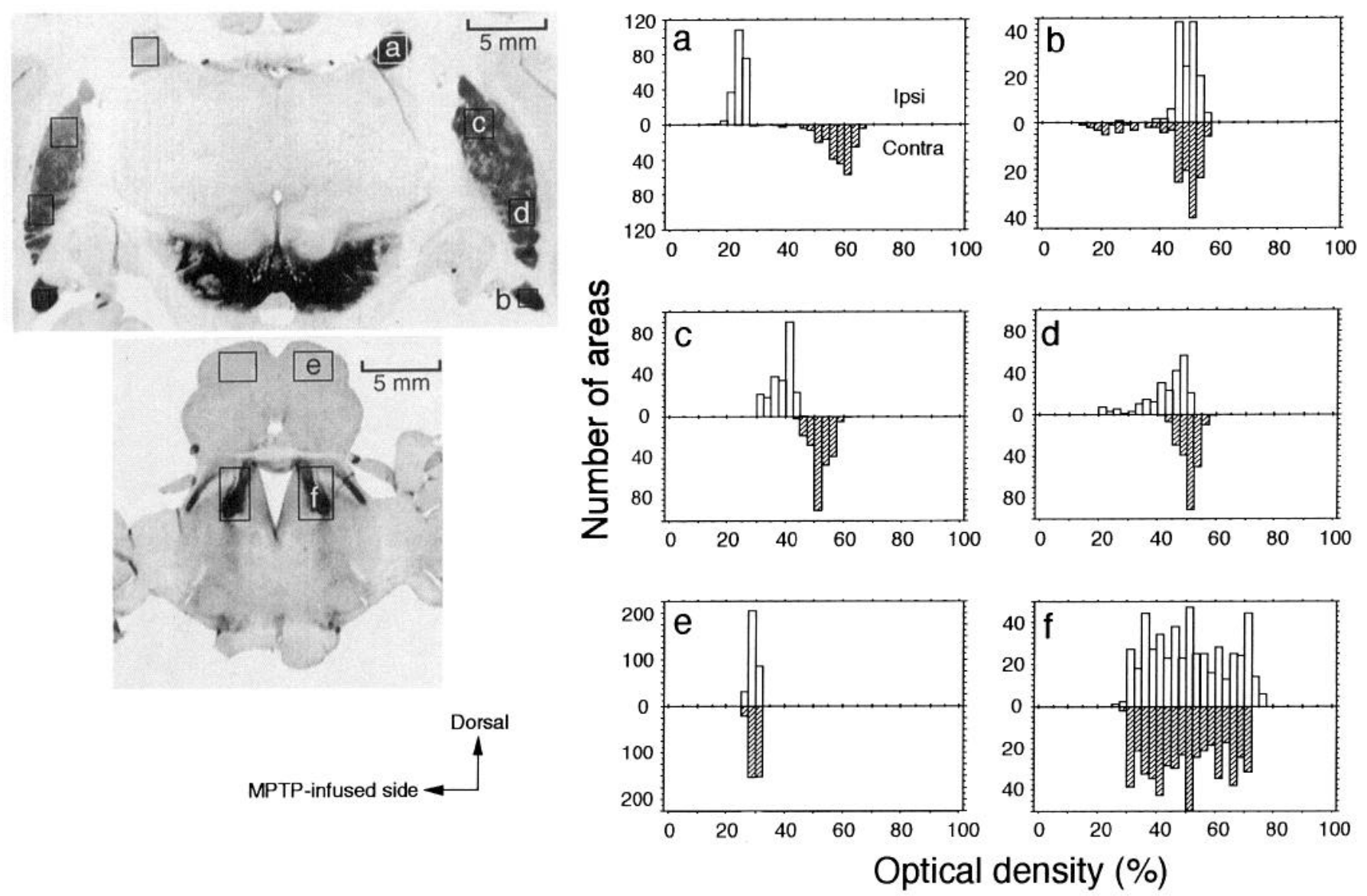

Figure 4. Scanner images showing TH immunoreactivity in the frontal sections at the levels of the posterior putamen (upper left) and the locus ceruleus (lower left). $a$, dorsal part of the caudate tail; $b$, ventral part of the caudate tail; $c$, dorsal portion of the putamen; $d$, ventral portion of the putamen; $e$, superior colliculus; $f$, locus ceruleus. Conventions are the same as Figure 2.

bens (Fig. 2). No cell loss was seen in the ventral tegmental area and the locus ceruleus (Fig. 4).

Figure 6 shows the mean decreases in optical density (ipsilateral side-contralateral side) in 24 areas of three monkeys. Some difference in the degree and distribution of dopamine loss was noticed among three monkeys. The lesion was localized in the Cd, especially its body, in the monkey PE, and less so in the monkey RO. The site of MPTP infusion was more rostral in the monkey IG, and the depletion was strongest in the caudate head and included a large part of the putamen.

These results indicate that MPTP infusion into the Cd specifically destroyed the dopaminergic neurons in the SNc projecting to the infusion site of the $\mathrm{Cd}$. We conclude that the oculomotor deficits described in the following should be attributed to the decrease of dopaminergic innervation onto the $\mathrm{Cd}$ and the dorsal portion of the putamen.

\section{Overview of general behaviors}

The monkey RO showed a postural change of the left hand (contralateral to the MPTP infusion) transiently for a few days after starting the infusion. Otherwise, little or no skeletomotor dysfunctions were found in this and other monkeys. They had a good appetite and appeared to be moving normally in their cages. Their postures appeared to be normal, showing no head turning or tilting. There were no signs of rigidity, bradykinesia, or tremor. The monkey IG showed periods of prolonged staring when he was in his cage; otherwise, his behavior did not differ from the other monkeys. No therapy was necessary such as administration of 1-DOPA.

\section{Overview of deficits in spontaneous eye movements}

In contrast to the general behavior, spontaneous eye movements changed clearly after the MPTP infusion. Table 1 summarizes the effects of unilateral MPTP infusion in the three monkeys together with the regional dopamine deficiencies. The most consistent effect was the shift of eye position to the infused side. Changes in saccade parameters were less consistent. The decrease in frequency was evident in monkeys RO and PE, not in the monkey IG, whereas the decrease in amplitude was clearest in the monkey IG. The decrease in velocity (coupled with the increase in duration) was most evident in the monkey PE.

We will first describe the nature of the changes qualitatively, and in the following sections analyze them quantitatively. An example is shown in Figure 7; the data were taken from the monkey RO in the light condition. In the normal monkey, spontaneous saccades were made within the central $40^{\circ}$ area (Fig. 7 , Pre MPTP, left). Such eye fixations were most frequent around the center of the screen which corresponded to the level of the eye (Fig. 7, Pre MPTP, right). The saccades were almost uniformly distributed in all directions, which was evident when they were aligned as if starting from the center (Fig. 7, Pre MPTP, center). The other two monkeys showed similar patterns of spontaneous eye movements.

These basic features were changed by an infusion of MPTP 

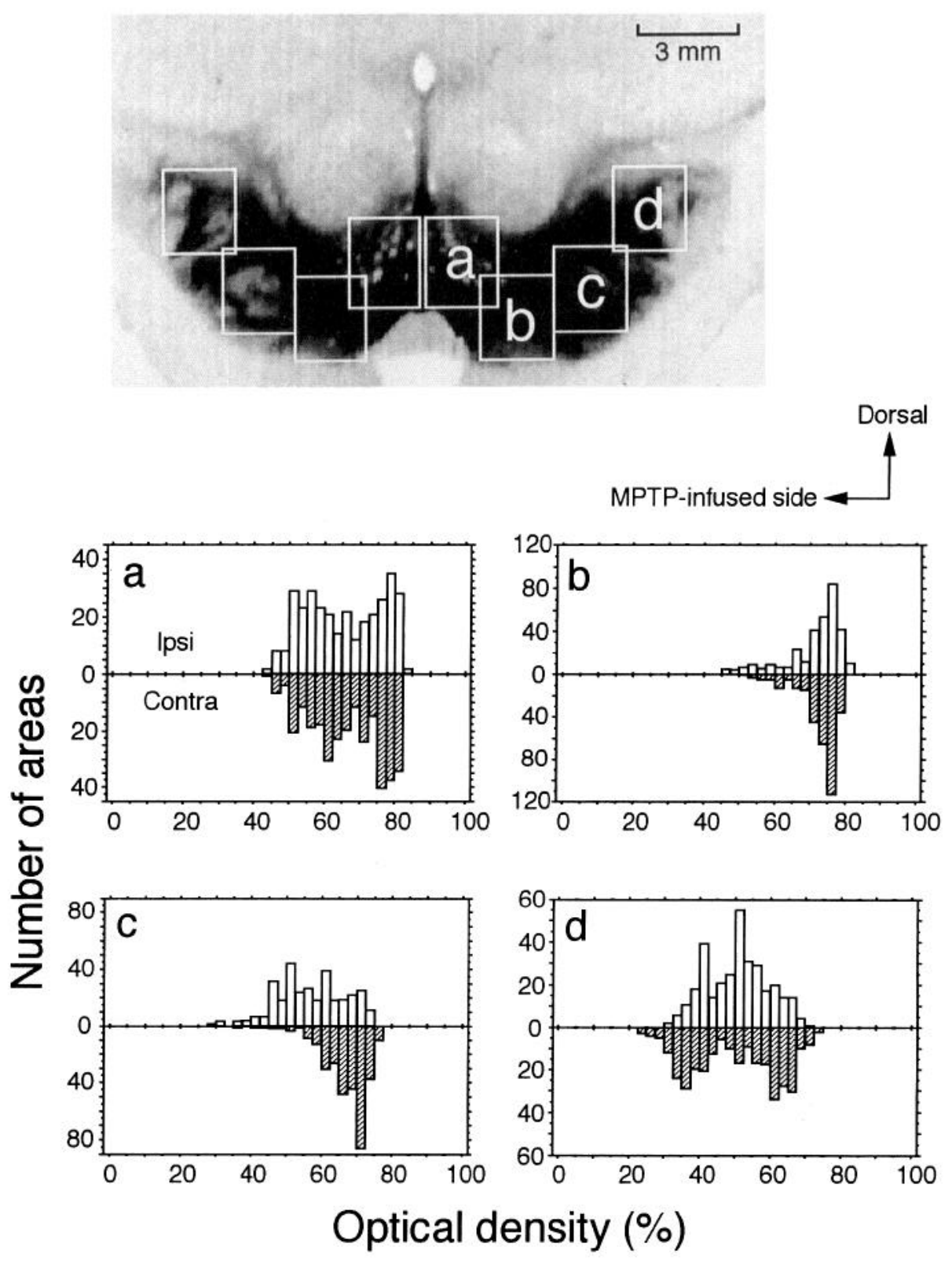

Figure 5. A scanner image showing TH immunoreactivity in the frontal section of the substantia nigra. $a$, Ventral tegmental area; $b-d$, medial, central, and lateral portions of the substantia nigra, respectively. Conventions are the same as Figure 2.

in the $\mathrm{Cd}$ on one side. From $2 \mathrm{~d}$ after the beginning of the MPTP infusion, the area scanned by the eye became smaller and shifted to the side ipsilateral to the infused side (Fig 7. Post MPTP, left). Saccades became smaller and their frequency decreased while their directions were still scattered (Fig 7. Post MPTP, center). The positions of eye fixation shifted to the ipsilateral side by about $10^{\circ}$, confined in a small area of $20^{\circ}$ width (Fig 7 . Post MPTP, right). These changes were strongest on day 10 (monkeys RO and IG) or day 20 (monkey PE), after which they recovered gradually.

As control experiments, these monkeys were infused with saline of the same amount as the MPTP solution, before (monkey PE), after (monkey RO), or simultaneously (monkey IG) with the MPTP infusion, into the Cd (see Materials and Methods). There were no effects after the saline infusions.

\section{Saccade frequency}

The frequency of saccades decreased in all directions. In each experiment we counted the number of saccades which occurred in a $3 \mathrm{~min}$ recording period. An example of its changes after MPTP infusion is shown in Figure 8 (monkey RO, the light condition). The frequency started decreasing by day 2 after the beginning of the infusion and the decrease continued for about $20 \mathrm{~d}$. The decrease was observed in both contralateral and ipsilateral directions of saccades. After the MPTP infusion ipsilaterally directed saccades were largely more frequent than contralaterally directed ones, which might contribute to the ipsilateral shift of eye position. After $20 \mathrm{~d}$ there was some hint of recovery in saccade frequency.

\section{Saccade amplitude}

The narrowing of the eye movement area (Fig. 7) may be related to the decrease in saccade amplitude (Fig. 9). In the normal monkey (Pre MPTP) there was a tendency for larger saccades to occur less frequently than smaller ones. The tendency was clearest in the dark condition. In addition, there were a group (or groups) of saccades of intermediate sizes (around 10-20\%; evident in the dim condition). After the MPTP infusion such 


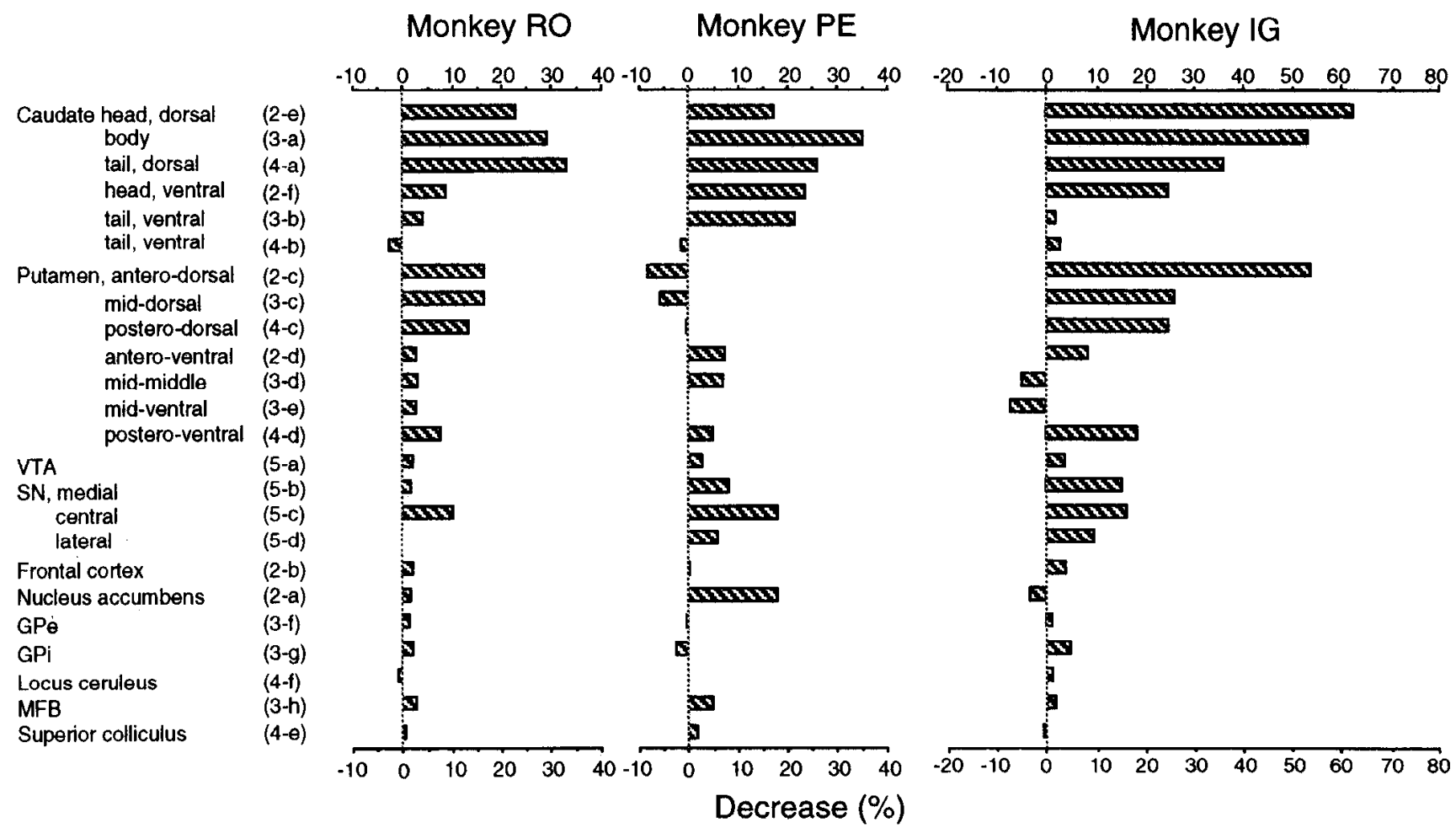

Figure 6. Differences of TH immunoreactivity between symmetrical areas ipsilateral and contralateral to the infusion site in three monkeys. The differences are shown as histograms indicating the mean decreases of optical density (the mean optical density of the contralateral side-that of the ipsilateral side). Numbers and lowercase characters on the left to the histograms indicate figure numbers and areas, respectively, where optical density was measured. $G P e$, external pallidum; $G P i$, internal pallidum; $M F B$, medial forebrain bundle; $S N$, substantia nigra; $V T A$, ventral tegmental area.

medium-sized saccades became much less frequent. The distributions were now of monotonically decreasing functions, irrespective of the illumination conditions (unlike before the infusion). Very small saccades predominated even in the light condition. The animal, however, could make larger $\left(>30^{\circ}\right)$ saccades.

\section{Saccade velocity}

Saccade velocity also decreased after the MPTP infusion. In Figure 10 , the peak velocities of saccades are plotted against the amplitudes of the saccades (monkey PE). The Pre MPTP distribution shows a well-documented pattern (Becker, 1989); an exponential-like increase with an asymptotic value around $800 \%$ sec. After the MPTP infusion, the peak velocity showed a general depression, especially for the saccades directed toward the side contralateral to the infusion site.

\section{Saccade duration}

The decrease in saccade velocity was coupled with the increase in saccade duration, as shown in Figure 11 (monkey PE). In the normal monkey (Pre MPTP) the duration/amplitude relationship was roughly linear, the intercept being about $25 \mathrm{msec}$. There were a number of saccades, however, that were deviated upward from the relationship (i.e., with longer durations). Such longer duration saccades became more frequent after the MPTP infusion, obscuring the linear relationship. The increase in duration was more prominent among the saccades directed toward the contralateral side.
Table 1. The effects of unilateral MPTP infusion into the $\mathrm{Cd}$ on spontaneous eye movements (top) and regional decreases of TH immunoreactivity (bottom)

\begin{tabular}{llll}
\multicolumn{4}{c}{ Monkey } \\
& RO & PE & IG \\
\cline { 2 - 4 } Saccade parameters & & & \\
Position (ipsi shift) & +++ & +++ & +++ \\
Frequency (decrease) & +++ & +++ & \pm \\
Amplitude (decrease) & $++/++$ & $+/+$ & $+++/+++$ \\
Velocity (decrease) & $+/++$ & $++/+++$ & $\pm /+$ \\
Duration (increase) & $+/++$ & $+++/++$ & $\pm / \pm$ \\
DA deficiency & & & \\
Caudate head & + & ++ & +++ \\
Caudate body & +++ & +++ & +++ \\
Putamen, anterior & \pm & - & +++ \\
Putamen, posterior & \pm & - & ++
\end{tabular}

Saccade parameters (top) were compared between pre- and post-MPTP (day 10 or 20) examinations; the number of + signs indicates the number of comparisons among the three illumination conditions that showed a significant change $(p<$ 0.0001 by Mann-Whitney $U$ test); \pm is indicated when none of the three comparisons reached the significance level $(p<0.0001)$ but any of them showed a less significant change $(p<0.001)$. For saccade amplitude, velocity, and duration, the effects are shown separately for saccades directed toward the side contralateral and ipsilateral (contra/ipsi) to the infusion site. TH immunoreactivity (bottom) was compared between the symmetric positions in four striatal areas (based on Fig. 6); the decrease in the MPTP-infused side was classified into $>30 \%(+++)$, $20-30 \%(++), 10-20 \%(+), 5-10 \%( \pm)$, and $<5 \%(-)$. 


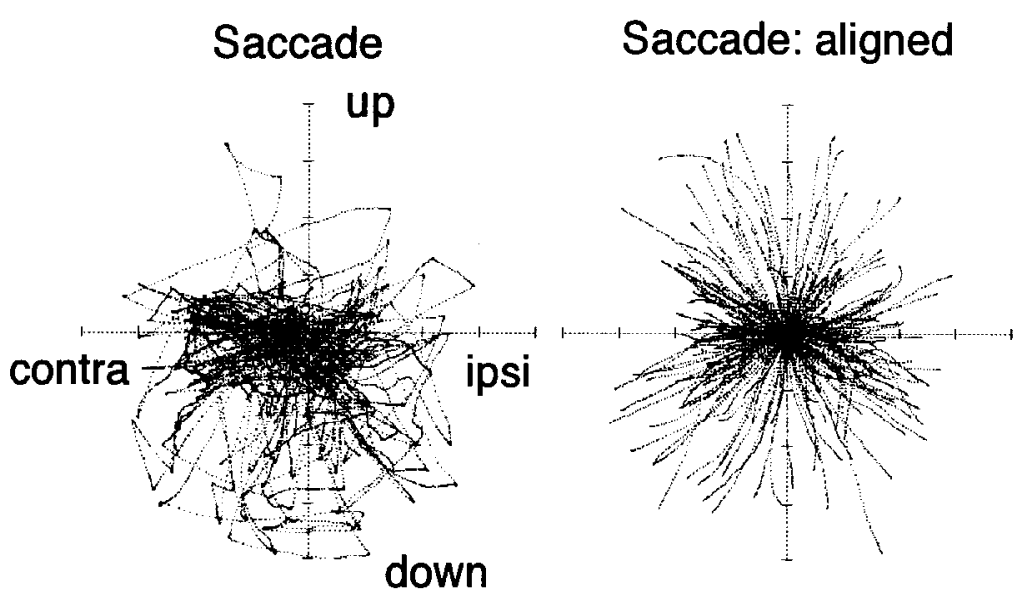

\section{Fixation}

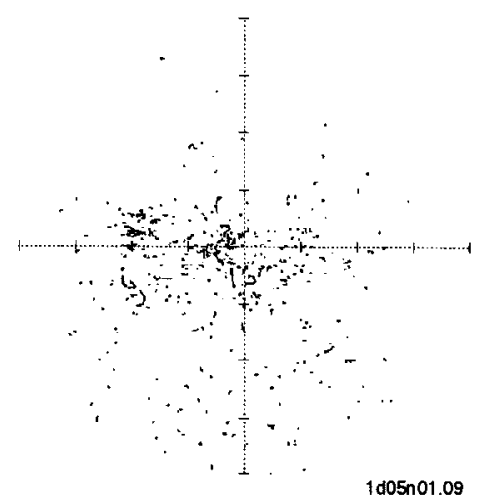

\section{Post MPTP}
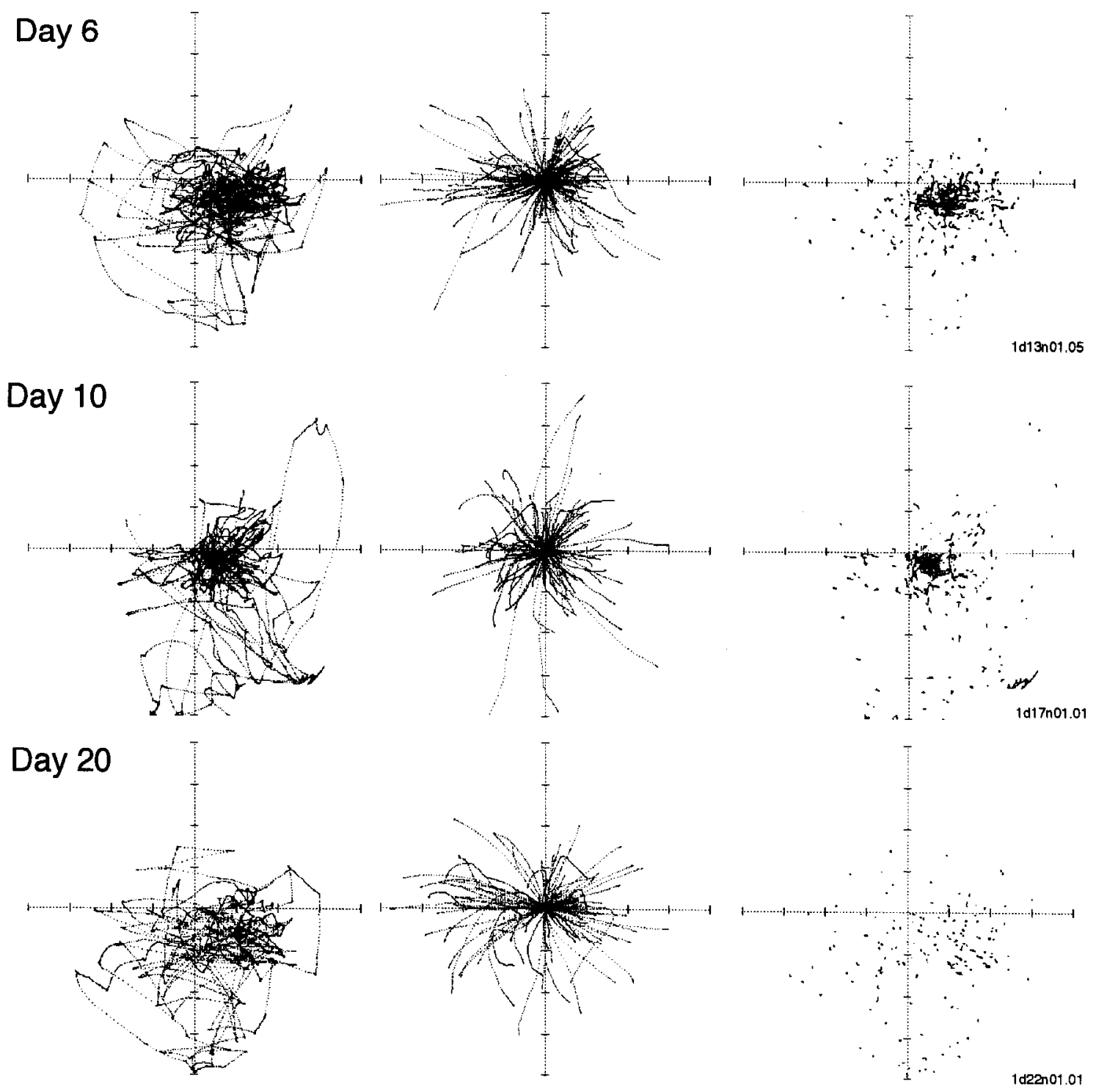

1 div. $=10^{\circ}$

Figure 7. Spontaneous eye movements shown as two-dimensional traces before (Pre MPTP) and 6, 10, and $20 \mathrm{~d}$ after (Post MPTP) starting MPTP infusion into the right Cd. Eye movements in a 3 min recording period are shown in three ways: left column, all saccades; center column, the same saccades are displayed as if starting from the center; right column, positions where the eye fixated between saccades. Data were taken from the monkey RO in the light condition. 


\section{Effects of dopamine agonist on spontaneous eye movements}

It is well known that rodents and cats with unilateral dopamine lesion show contralateral turning in response to dopamine agonists (Ungerstedt and Arbuthnott, 1970), suggesting a receptor supersensitivity. In the present study, we examined the effects of dopamine agonists on our unilateral dopamine deficient monkeys.

Figure 12 shows the change in spontaneous eye movements by apomorphine injected intramuscularly in the monkey PE. The data were obtained $36 \mathrm{~d}$ after the MPTP infusion. Before injection of apomorphine, the area scanned by the eye, on the average, was deviated to the side ipsilateral to the MPTP infused side, as described above. This asymmetry was reversed shortly after the apomorphine. The eye now shifted to the contralateral side by about $30^{\circ}$, confined in a smaller area of about $10^{\circ}$ width. The frequency of saccades increased in the light condition (before 308/after 417 for $3 \mathrm{~min}$ ) but decreased in the dim condition $(289 / 219)$. The velocity increased for contralaterally directed saccades, but decreased for ipsilaterally directed saccades. In general, the apomorphine administration reversed the effects of MPTP infusion. Qualitatively similar effects were obscrved in the other monkeys.

\section{Discussion}

We have shown that local MPTP infusion unilaterally into the caudate nucleus $(\mathrm{Cd})$ caused marked depletion of dopaminergic fibers in the Cd and the dorsal portion of the putamen ipsilateral to the infusion site. After the MPTP infusion, the frequency, amplitudes and peak velocities of spontaneous saccades decreased. These effects were observed in both directions of the saccades but more prominent for the saccades directed toward the side contralateral to the infusion site. The area scanned by the eye of the animal shifted to the side ipsilateral to the infusion site.

\section{Oculomotor-selective effects of MPTP infusion into the caudate} nucleus

Lively eye movements, which characterize monkey's facial expression, were lost after infusion with a small amount of MPTP unilaterally into the $\mathrm{Cd}$, even though monkeys were otherwise active in performing daily acts. Similar oculomotor deficits were consistent with earlier studies (Brooks et al., 1986; Schultz et al., 1989a). In these studies, monkeys showed parkinsonian symptoms because MPTP was administered bilaterally by the intravenous or intracarotid injection, the method which is thought to destroy not only the dopaminergic neurons in the substantia nigra pars compacta (SNc) but also other monoaminergic neurons. The possibility remained that the oculomotor deficits might be attributed to the dysfunction of areas other than the basal ganglia. Using a local infusion method we were able to show that the dopaminergic denervation was localized yet the oculomotor, but not skeletomotor, deficits were significant.

Why was the MPTP effect limited to eye movement? The decrease of tyrosine hydroxylase ( $\mathrm{TH}$ ) activity was strongest in the $\mathrm{Cd}$ around the infusion site, although slight to significant decreases were observed in the dorsal part of the putamen. This part of the $\mathrm{Cd}$ contains a group of saccadic/visual/cognitive neurons (Hikosaka et al., 1989); few neurons are related, at least in a simple way, to skcletal movements. A significant decreasc of TH activity in the putamen was observed in the monkey IG,

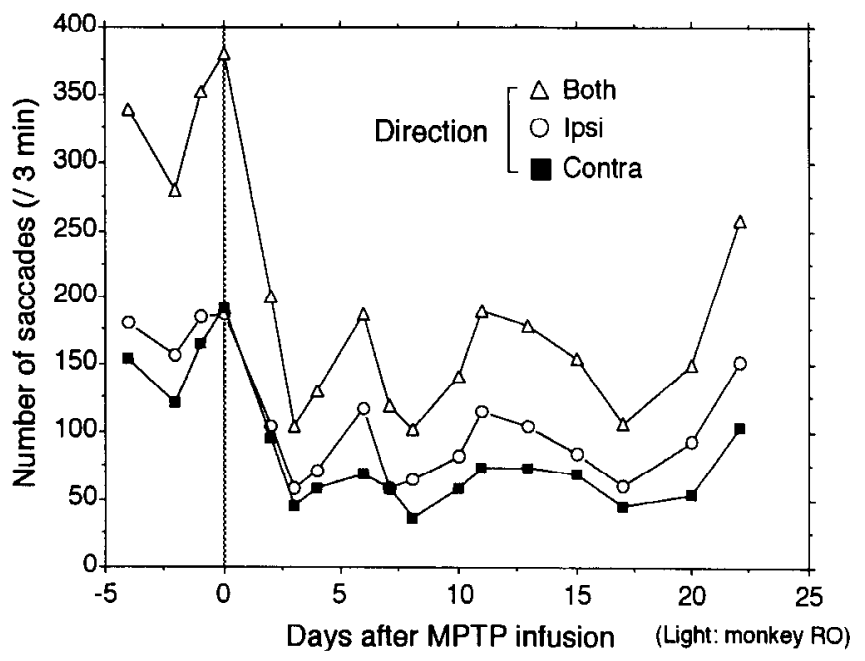

Figure 8. Changes of the number of saccades in a $3 \mathrm{~min}$ recording period before and after MPTP infusion. Day 0 indicates the beginning of the infusion. Ipsi and Contra indicate the numbers of saccades with directions ipsilateral and contralateral to the infusion side, respectively; their sum is shown as Both. Data from the monkey RO in the light condition.

whose skeletal movements, unlike the other monkeys, became slightly slower (see Kori et al., 1994). These results are in line with the functional segregation hypothesis that the $\mathrm{Cd}$ is related to oculomotor (and perhaps cognitive) functions whereas the pulamen is related to skeletomotor functions (Alexander and Crutcher, 1990). However, we cannot exclude the possible skeletomotor functions of the $\mathrm{Cd}$, because we examined only a simple reaction time task.

\section{Mechanism of spontaneous eye movements}

Monkeys as well as humans make saccades spontaneously even if there is no demand, as in total darkness, to foveate an object. Neuronal activity related to such spontaneous saccades has not been found in the substantia nigra pars reticulata (SNr), which is the output portion of basal ganglia related to eye movement (Hikosaka and Wurtz, 1983a). In the Cd, which is the input portion of basal ganglia related to eye movement, some of the cells with the activity related to memory-guided saccade showed discharges with spontaneous saccades; however, the activity was less clear than seen with task-related saccades (Hikosaka et al., 1989).

The present results, however, suggest that the basal ganglia control spontaneous saccades as well. What might be the underlying mechanism? The role of the basal ganglia in spontaneous saccades is probably nonspecific, determining the probability of saccades. The signals that determine the timing of each saccade may originate in the cerebral cortical areas (e.g., frontal eye field or supplementary eye field) or even in the brainstem, but may be gated on or off by the nigrocollicular inhibition. The sustained enhancement of nigrocollicular inhibition, the probable outcome of the MPTP infusion in the Cd, would tend to negate the potential saccadic signals impinging on the superior colliculus.

\section{Ipsilateral shift of eye position}

Unilateral MPTP infusion induced a remarkable shift of eye position to the infusion sidc. This change was observed in all the three monkeys and remained robust even after other saccade 
Contralateral Pre MPTP

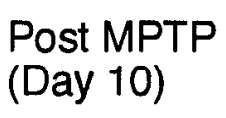
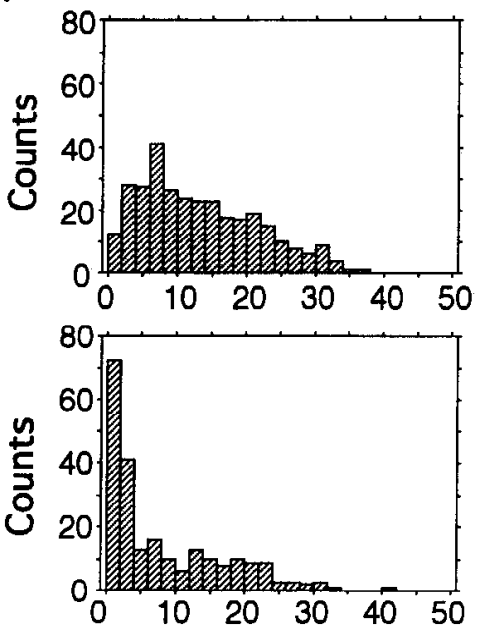

Dim
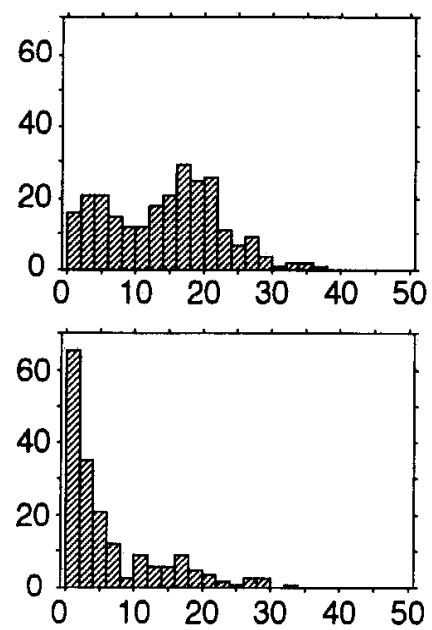

Dark
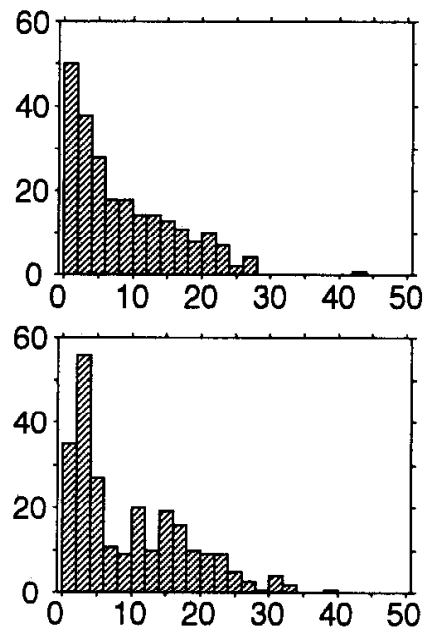

\section{Ipsilateral}
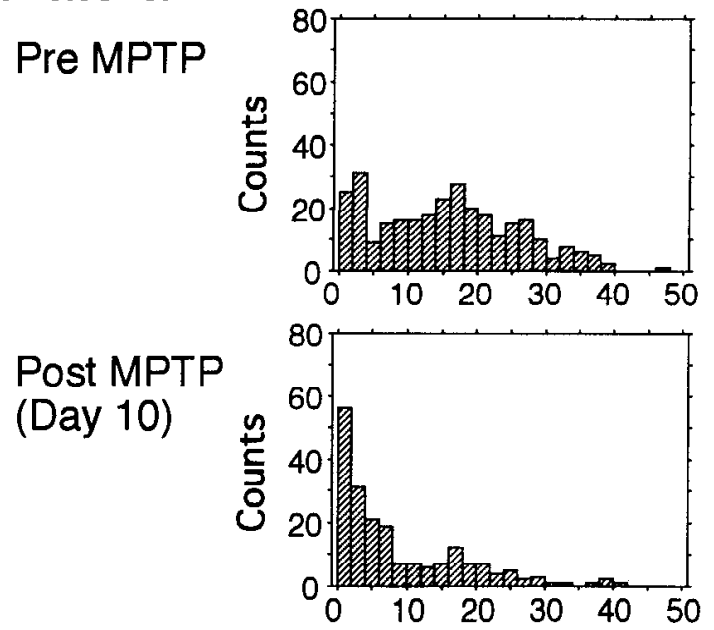
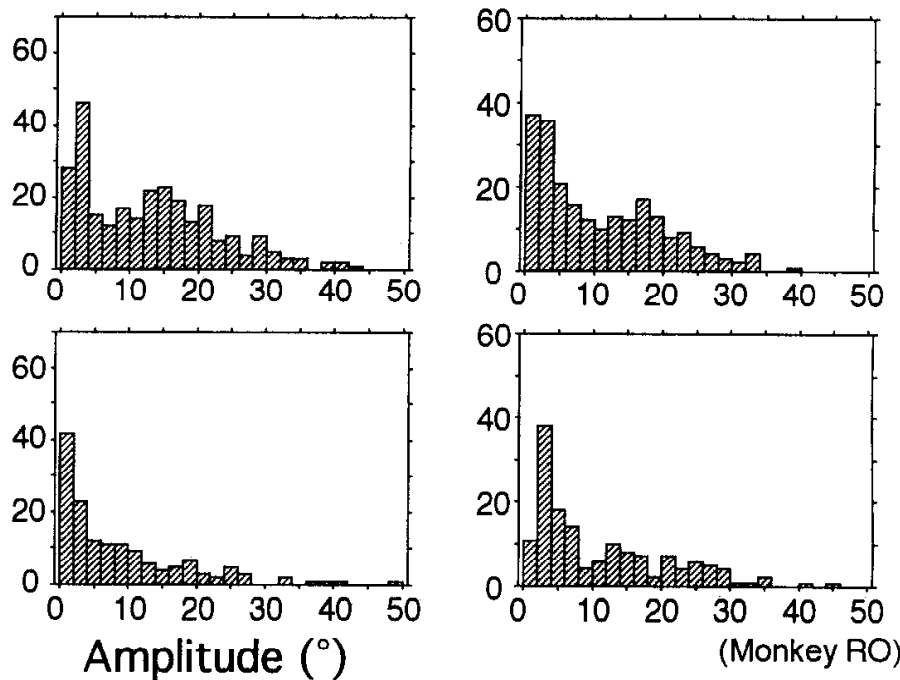

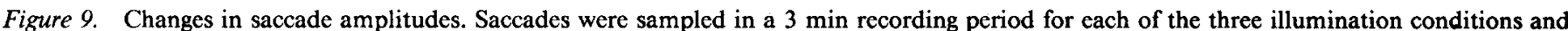

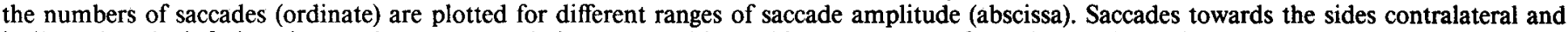
ipsilateral to the infusion site are shown separately in upper and lower histograms. Data from the monkey RO.

parameters started recovering. In the following we will discuss on the possible mechanism underlying the eye position shift.

Since the activity of $\mathrm{Cd}$ neurons is thought to be transmitted to $\mathrm{SNr}$ neurons (Hikosaka, 1989), it is reasonable to assume that the eye position effect is caused by the change in activity of the structures innervated by the $\mathrm{SNr}$, such as the superior colliculus or the thalamus. Neurons in the superior colliculus encode the vector of saccade, usually unrelated to eye position in the orbit (Sparks, 1986). In the thalamus (part of mediodorsal nucleus and the adjacent paracentral intralaminar nucleus), however, were found neurons that showed changes of firing as a function of eye position (Schlag and Schlag-Rey, 1984).

Relevant in this regard is the series of study by Albano and her colleagues (Albano et al., 1982; Albano and Wurtz, 1982) in which the superior colliculus and the posterior-medial thalamus were ablated in the monkey. The monkeys whose lesions included the thalamus showed an eye position error in which saccades to contralateral (not ipsilateral) visual targets fell short and subsequent gaze was not corrected (Albano et al., 1982). In addition to the saccadic and visual deficits, the pattern of spontaneous eye movements changed so that the monkeys tended to look toward the side ipsilateral to the ablation (Albano and Wurtz, 1982). These results were strikingly similar to our observations. It is thus conceivable that the ipsilateral gaze shift induced by unilateral dopamine deficiency was mediated by the nigral projections to the superior colliculus or the posteriormedial thalamus.

The influence of the caudate-nigral signals may then be traced through the thalamic areas to some cortical areas. The frontal eye field contains eye position-related ncurons (Bizzi, 1968; Bruce and Goldberg, 1985; Segraves, 1992). In the supplementary eye field (SEF), which is also likely to be influenced by the $\mathrm{SNr}$ (Huerta and Kaas, 1990; Schall, 1991), Huerta and Kaas (1990), Schall (1991), and Schlag et al. (1992) found eye position-related activity, but the activity change occurred only under the condition of active fixation and did not appear when the animal 
Pre MPTP

\section{Contralateral}

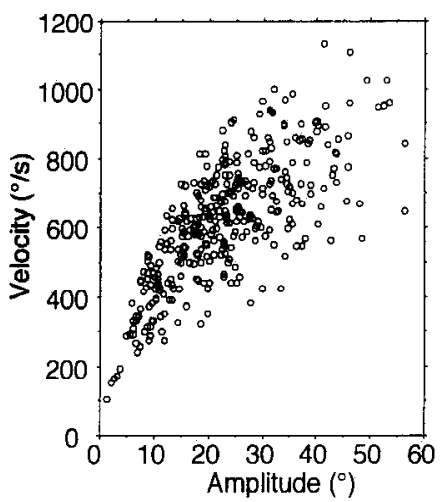

Ipsilateral
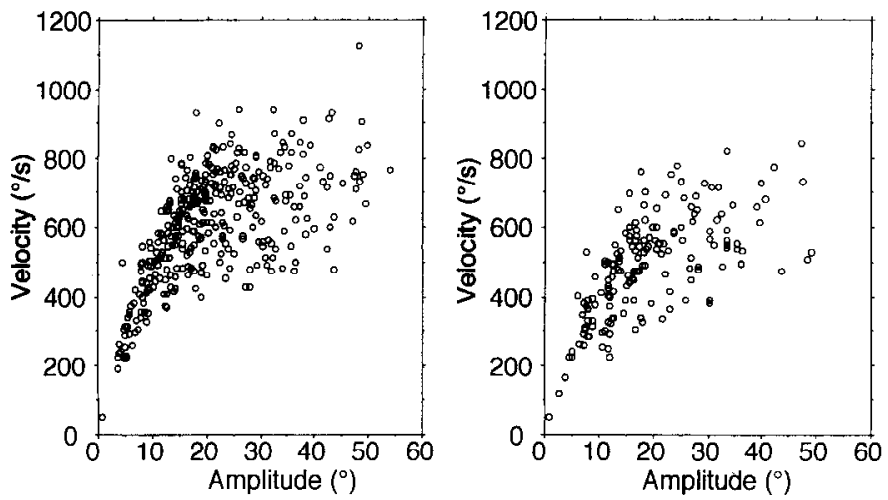

(Dim: monkey PE)

Figure 10. Change in peak velocity/amplitude relationship. Saccades were sampled in a $3 \mathrm{~min}$ recording period in the dim condition in the monkey PE, before (Pre MPTP) and after (Post MPTP, Day 20) infusion. Upper and lower plots show the saccades toward the side contralateral and ipsilateral to the infusion sitc, respectivcly.

spontaneously oriented. The parietal cortex may also be under the influence of the SNr through the SNr-recipient thalamic nuclei (Kasdon and Jacobson, 1978); eye position is a major signals carried by neurons in the lateral intraparietal area (Andersen et al., 1990).

Thus, eye position related activity is found in many areas receiving inputs directly or indirectly from the $\mathrm{SNr}$. The Cd$\mathrm{SNr}$ system may participate in controlling eye position through these areas, although the eye position-related activity has not been described in the SNr. Compared with a previous finding showing the contralateral shift of eye position by suppression of $\mathrm{SNr}$ cell activities (Hikosaka and Wurtz, 1985b), the ipsilateral shift by the MPTP-infusion suggests that the dopamine depletion causes the increase in the activity of ipsilateral $\mathrm{SNr}$ neurons. This is consistent with the present finding that the saccadic velocity decreased in the same animals.

There can be two possible mechanisms to account for the eye position shift: (1) directional imbalance of saccade probability, and (2) shift of primary eye position. According to the first mechanism, the current eye position depends on the stochastic process of preceding saccades. Suppose the probability of rightward saccades is twice larger than that of leftward saccades, eye position would shift rightward from the original position. This mechanism could explain the contralateral shift of eye position after a muscimol injection into the $\mathrm{SNr}$ (Hikosaka and Wurtz,
Pre MPTP

Post MPTP (Day 20)

\section{Contralateral}
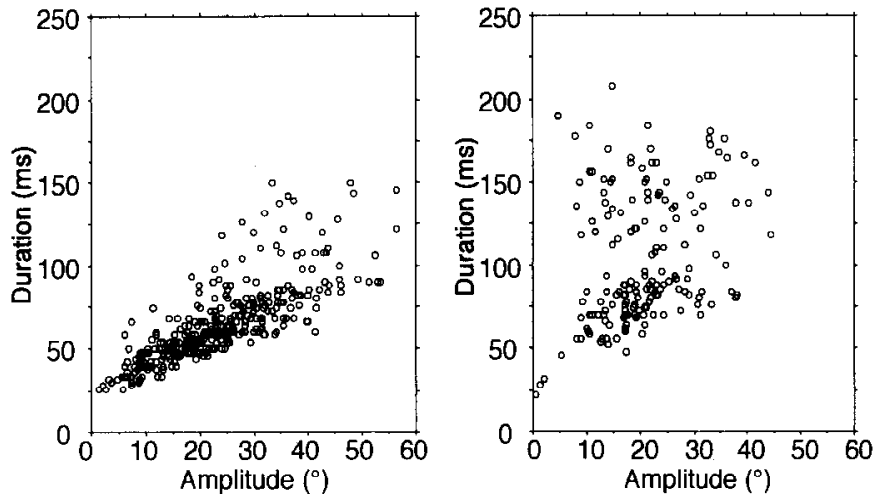

Ipsilateral
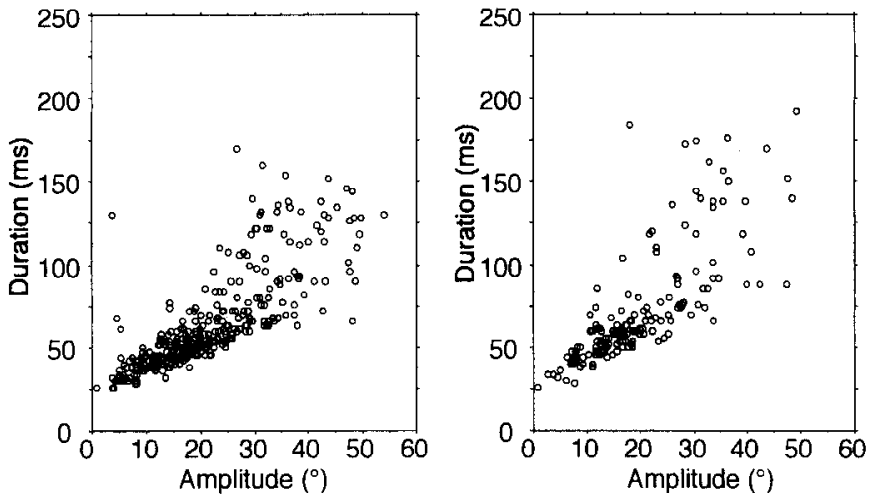

(Dim: monkey PE)

Figure 11. Changes in saccade duration/amplitude relationship. The data were obtained from the same saccades as shown in Figure 10.

1985b); here the tonic inhibition of the $\mathrm{SNr}$ on the superior colliculus was removed, leading to continual saccades to the contralateral side, with virtually no ipsilateral saccades. However, it seems unlikely that the same explanation can be applied to the MPTP-induced eye position shift, because saccades in our MPTP monkeys were infrequent and small in both directions (Fig. 8, Table 1).

The second explanation postulates the mechanism to determine the primary eye position in the orbit. A normal awake animal tends to make saccades toward the central position in the orbit, which could tentatively be called primary eye position. It looked as if, in the MPTP-infused monkeys, the primary eye position was shifted toward the infusion site. The basal ganglia would thus play a critical role in determining the primary eye position.

There has been little evidence suggesting the existence of such a mechanism. A hypothetical explanation would be to postulate the interaction between the saccadic mechanism and the eye position mechanism such that, for example, the threshold for activation of the rightward saccade mechanism would be lowered when the eye is deviated to the left. The origin of the eye position signal may be (1) the efference copy of eye movement commands, as seen in the prepositus hypoglossi nucleus (Baker et al., 1975; Hikosaka et al., 1978) or the interstitial nucleus of Cajal (Fukushima, 1991), or (2) proprioceptive afferents from the extraocular muscles (Roll et al., 1991). How the basal ganglia might modify the mechanism remains an intriguing question. 


\section{Saccade}

Saccade: aligned

Fixation

\section{Pre apomorphine (Post MPTP, Day 36)}
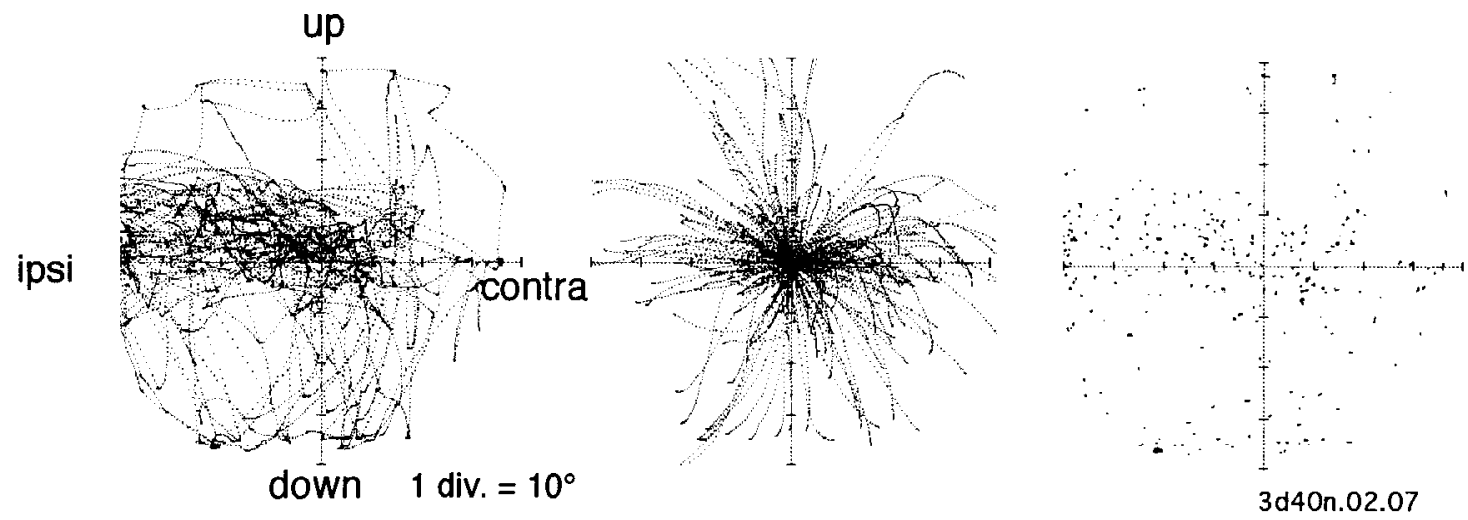

\section{Post apomorphine}
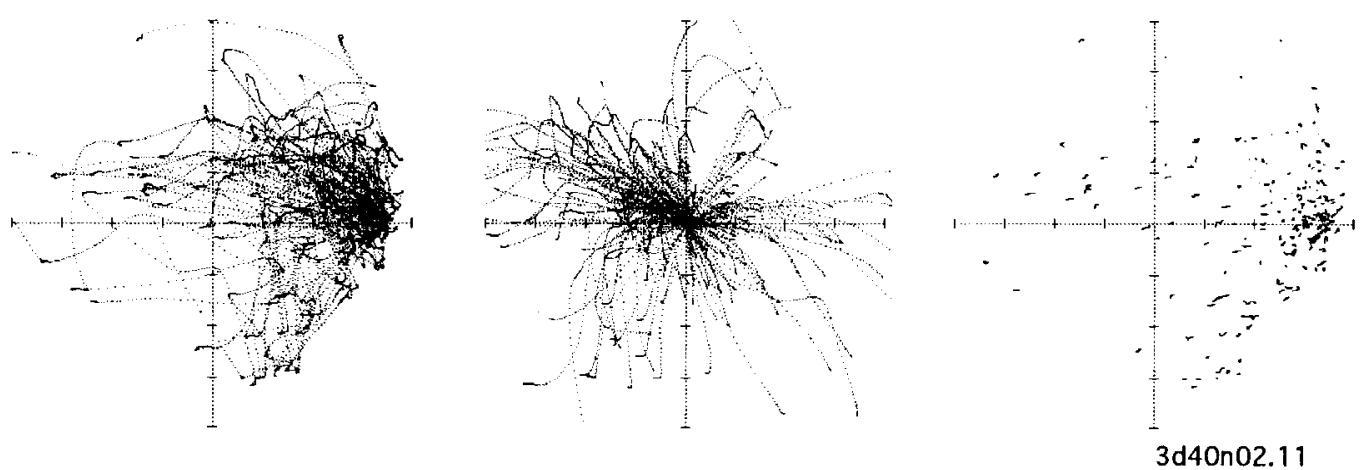

3d40n02.11

(Monkey PE, dim)

Figure 12. Spontaneous eye movements shown as two-dimensional traces before (Pre apomorphine) and 8 min after (Post apomorphine) an apomorphine injection on day 36 after MPTP infusion. Eye movements in a 3 min recording period are shown in three ways (see Fig. 7). Data were taken from the monkey PE in the dim condition.

The primary eye position effect is reminiscent of the skeletal postural changes in basal ganglia disorders which have been observed in human patients (Selby, 1968) as well as in experimental animals (Langston, 1985).

\section{Bidirectional effects on spontaneous saccades by unilateral MPTP infusion}

The bilateral effects of unilateral MPTP infusion observed in this study might suggest that the $\mathrm{Cd}$ has bidirectional control over spontaneous saccades. It seems unlikely that the underlying mechanism is present inside the basal ganglia. Since the SNc projects to the ipsilateral $\mathrm{Cd}$ and putamen (Carpenter and Peter, 1972; Carpenter et al., 1976; Szabo, 1980), it is unlikely that unilateral retrograde degeneration of dopaminergic fibers affects the dopamine system in both hemispheres. The $\mathrm{Cd}$ also projects ipsilaterally to the SNr (Voneida, 1960; Szabo, 1962; Grofova, 1975). Neurons in the Cd (Hikosaka et al., 1989) and the $\mathrm{SNr}$ (Hikosaka and Wurtz, 1983a) carry signals related to mostly, not exclusively, contralaterally directed saccades.
There may be some possibility of bilateral innervation outside the basal ganglia. Some neurons in the $\mathrm{SNr}$ send outputs to target areas bilaterally, although the contralateral projection is much sparser than the ipsilateral one (Hopkins and Niessen, 1976; Jayaraman et al., 1977; Huerta et al., 1991). For the nigrothalamic projections, some $\mathrm{SNr}$ neurons project bilaterally to the lateral part of the mediodorsal and the adjacent paracentral intralaminar nuclei (Russchen et al., 1987). Therefore, the activity change of the $\mathrm{SNr}$ ipsilateral to the MPTP infusion might affect the activity in target structures of basal ganglia on both sides and cause changes in saccadic parameters bilaterally.

\section{Effects of dopamine depletion on activity of SNr and striatal neurons}

In the present study, the frequency, amplitude, and peak velocity of spontaneous saccades were decreased after MPTP infusion. The results would be expected if the activity of $\mathrm{SNr}$ neurons is abnormally increased, as judged by the previous studies. A similar, but stronger, suppression of saccades was produced by the 
muscimol-induced suppression of neural activity in the superior colliculus, which is considered to mimic an enhancement of $\mathrm{SNr}$ activity (Hikosaka and Wurtz, 1985a). Conversely, the suppression of $\mathrm{SNr}$ activity caused facilitation of contralaterally directed saccades (Hikosaka and Wurtz, 1985b). This is consistent with the observation in MPTP-induced parkinsonian monkeys that the mean spontaneous firing rate was increased in neurons of the internal segment of globus pallidus (GPi), a major skeletomotor output of the basal ganglia (Bergmann et al., 1990; Filion and Tremblay, 1991).

Why should the outputs of the basal ganglia increase by dopamine depletion? Let us consider three possibilities. First, the lack of dopamine released from the dendrites of SNc neurons might lead to a disinhibition of $\mathrm{SNr}$ cell activities, provided that dopamine is inhibitory on SNr neurons. Second, an excitatory effect of dopamine on $\mathrm{Cd}$ neurons might be reduced by dopamine depletion, leading to a disinhibition of $\mathrm{SNr}$ neurons through a direct connection. Third, an inhibitory effect of dopamine on Cd neurons might be reduced, leading to an enhanced excitation of $\mathrm{SNr}$ neurons through an indirect connection via the external segment of the globus pallidus (GPe) and the subthalamic nucleus (STN).

The first hypothesis assumes that the effect of dopamine on SNr neurons is inhibitory. But the evidence available does not support the idea. Thus, $\mathrm{SNr}$ neurons are activated by iontophoretically applied dopamine (Ruffieux and Schultz, 1980); a $D_{1}$ agonist increases the firing rate and a $D_{2}$ agonist attenuates the inhibitory responses to GABA or striatal stimulation (Waszczak and Walters, 1983; Waszczak et al., 1984; Waszczak, 1990).

The critical site of dopamine action would then be the striatum. It is thought that there are two types of output neurons in the striatum (Alexander and Crutcher, 1990). The first type projects to the output structures of the basal ganglia: the $\mathrm{SNr}$ and the GPi. Its activation would lead to a disinhibition of target structures (e.g., superior colliculus) (Deniau and Chevalier, 1985; Hikosaka and Wurtz, 1989). The second type projects to the GPe; its signal would then be transmitted, via the STN, to the output structures (Kanazawa et al., 1976; Kita et al., 1983; Kita and Kitai, 1987; Parent and Smith, 1987; Mitchell et al., 1989). Since this indirect pathway contains two inhibitions (striatumGPe and GPe-STN), unlike in the direct pathway which contains only one inhibition (striatum-SNr/GPi), its outcome would be an enhanced inhibition of target structures.

Gerfen et al. (1990) have suggested that dopamine has differential effects on these two types of striatal neurons through different receptors. The dopaminergic action on direct striatal neurons is mediated by $D_{1}$ receptors and facilitatory, whcreas the action on indirect striatal neurons is mediated by $D_{2}$ receptors and inhibitory. Interestingly, the final results of these dopaminergic actions would be the same, both resulting in a decrease of basal ganglia outputs. Stimulation of $D_{1}$ receptors would activate the direct striatal neurons, thereby inhibiting the output neurons in the basal ganglia; stimulation of $\mathrm{D}_{2}$ receptors would inactivate the indirect striatal neurons, disinhibit GPe neurons, and suppress STN neurons, thereby decreasing the basal ganglia outputs. In either case, neurons in the target structures (superior colliculus, thalamus, etc.) would be released from the tonic inhibition by the basal ganglia; initiation of movements would be facilitated.

It is thus expected that blockade of either $D_{1}$ or $D_{2}$ receptor activation leads to the inhibition of movement initiation, as seen in the present study. MPTP could have affected the $D_{1}$ mechanism, $D_{2}$ mechanism, or both; leading to the sustained enhancement of nigrocollicular inhibition.

If iontophoretically applied, however, the action of dopamine on striatal neurons is usually inhibitory. $D_{1}$ receptor activation decreases the excitability of striatal cells (Calabresi et al., 1987). Removal of the dopaminergic input after a 6-dihydroxydopamine-induced lesion results in increased spontaneous activity in striatal cells (Schultz and Ungerstedt, 1978). The release of endogenous dopamine decreases the terminal excitability of corticostriatal afferents (Garcia-Munoz et al., 1991). These results favor the third possibility, rather than the second, that the effect of dopamine depletion is mediated by the indirect pathway, as hypothesized for the mechanism of parkinsonism (Bergmann et al., 1990).

\section{Heterogeneity in the basal ganglia}

There were some differences between the three monkeys in the changes in spontaneous eye movements, as summarized in Table 1 . While the shift of eye position to the infused side was consistently observed in all monkeys, changes in saccade parameters were different between the monkeys. The decrease in frequency was evident in monkeys RO and PE, not in the monkey IG, whereas the decrease in amplitude was clearest in the monkey IG. The decrease in velocity was most evident in the monkey PE.

When these features are compared with the distribution of dopamine deficiency in the striatum, some speculations might be suggested. First, since the ipsilateral shift of eye position was present in all monkeys and the dopamine deficiency was commonly most intense in the body of the $\mathrm{Cd}$, it might be speculated that the $\mathrm{Cd}$ participates in maintaining eye position. Second, since the saccade amplitude decreased in monkey IG in which the putamen was relatively more affected, the putamen might play some role in maintaining saccade amplitudes. Third, since the saccade frequency and velocity decreased significantly in monkey RO and PE, but not in IG, these parameters might depend on the function of the $\mathrm{Cd}$. Differences between monkeys were also observed in task-specific saccades, which will be discussed in the following companion article (Kori et al., 1994).

\section{References}

Albano JE, Wurtz RH (1982) Deficits in eye position following ablation of monkey superior colliculus, pretectum, and posterior-medial thalamus. J Neurophysiol 48:318-337.

Albano JE, Mishkin M, Westbrook LE, Wurtz RH (1982) Visuomotor deficits following ablation of monkey superior colliculus. J Neurophysiol 48:338-351.

Alexander GE, Crutcher MD (1990) Functional architecture of basal ganglia circuits: neural substrates of parallel processing. Trends Neurosci 13:266-271.

Andersen RA, Bracewell RM, Barash S, Gnadt JW, Fogassi L (1990) Eye position effects on visual, memory, and saccade-related activity in areas I.IP and 7a of macaque. J Neurosci 10:1176-1196.

Baker R, Gresty M, Berthoz A (1975) Neuronal activity in the prepositus hypoglossi nucleus correlated with vertical and horizontal eye movement in the cat. Brain Res 101:366-371.

Becker W (1989) Metrics. In: The neurobiology of saccadic eye movements (Wurtz RH, Goldberg ME, eds), pp 13-67. Amsterdam: Elsevier.

Bergmann H, Wichmann T, DeLong MR (1990) Reversal of experimental parkinsonism by lesions of the subthalamic nucleus. Science 249:1436-1438.

Bergstrom DA, Walters JR (1984) Dopamine attenuates the effects of GABA on single unit activity in the globus pallidus. Brain Res 310 : 23-33.

Bizzi E (1968) Discharge of frontal eye field neurons during saccadic 
and following eye movements in unanesthetized monkeys. Exp Brain Res 6:69-80.

Brooks BA, Fuchs AF, Finocchio D (1986) Saccadic eye movement deficits in the MPTP monkey model of Parkinson's disease. Brain Res 383:402-407.

Bruce CJ, Goldberg ME (1985) Primate frontal eye fields. I. Single neurons discharging before saccades. J Neurophysiol 53:603-635.

Calabresi P, Mercuri N, Stanzione P, Stefani A, Bernardi G (1987) Intracellular studies on the dopamine-induced firing inhibition of neostriatal neurons in vitro: evidence for D1 receptor involvement. Neuroscience 20:757-771.

Carpenter MB, Peter P (1972) Nigrostriatal and nigrothalamic fibers in the rhesus monkey. $J$ Comp Neurol 144:93.

Carpenter MB, Nakano K, Kim R (1976) Nigrothalamic projections in the monkey demonstrated by autoradiographic technics. J Comp Neurol 165:401-416.

Chiodo LA, Berger TW (1986) Interactions between dopamine and amino acid-induced excitation and inhibition in the striatum. Brain Res 375:198-203.

Deniau JM, Chevalier G (1985) Disinhibition as a basic process in the expression of striatal functions. II. The striato-nigral influence on thalamocortical cells of the ventromedial thalamic nucleus. Brain Res 334:227-233.

Elsworth JD, Deutch AY, Redmond DE Jr, Taylor JR, Sladek JR Jr, Roth RH (1989) Symptomatic and asymptomatic 1-methyl-4-phenyl-1,2,3,6-tetrahydropyridine treated primates: biochemical changes in striatal regions. Neuroscience 33:323-331.

Filion M, Tremblay L (1991) Abnormal spontaneous activity of globus pallidus neurons in monkeys with MPTP-induced parkinsonism. Brain Res 547:142-151.

Fukushima K (1991) The interstitial nucleus of Cajal in the midbrain reticular formation and vertical eye movement. Neurosci Res 10:159187.

Garcia-Munoz M, Young SJ, Groves PM (1991) Terminal excitability of the corticostriatal pathway. I. Regulation by dopamine receptor stimulation. Brain Res 551:195-206.

Gerfen CR, Engber TM, Mahan LC, Susel Z, Chase TN, Monsma JFJ, Sibley DR (1990) D1 and D2 dopamine receptor-regulated gene expression of striatonigral and striatopallidal neurons. Science 250 : 1429-1432.

Gerfen CR, McGinty JF, Young IWS (1991) Dopaminc diffcrentially regulates dynorphin, substance $P$, and enkephalin expression in striatal neurons: in situ hybridization histochemical analysis. J Neurosci 11:1016-1031.

German DC, Dubach M, Askari S, Speciale SG, Bowden DM (1988) 1-Methyl-4-phenyl-1,2,3,6-tetra-hydropyridine-induced parkinsonian syndrome in Macaca fascicularis: which midbrain dopaminergic neurons are lost? Neuroscience 24:161-174.

Graham WC, Clarke CE, Boyce S, Sambrook MA, Crossman AR, Woodruff GN (1990) Autoradiographic studies in animal models of hemi-parkinsonism reveal dopamine D2 but not D1 receptor supersensitivity. II. Unilateral intra-carotid infusion of MPTP in the monkey. Brain Res 514:103-110.

Graybiel AM (1990) Neurotransmitters and neuromodulators in the basal ganglia. Trends Neurosci 13:244-253.

Grofova I (1975) The identification of striatal and pallidal neurons projecting to substantia nigra. An experimental study by means of retrograde axonal transport of horseradish peroxidase. Brain Res 91: 286-291.

Hikosaka O (1989) Role of basal ganglia in saccades. Rev Neurol (Paris) 145:580-586.

Hikosaka O, Wurtz RH (1983a) Visual and oculomotor functions of monkey substantia nigra pars reticulata. I. Relation of visual and auditory responses to saccades. J Neurophysiol 49:1230-1253.

Hikosaka O, Wurtz RH (1983b) Visual and oculomotor functions of monkey substantia nigra pars reticulata. IV. Relation of substantia nigra to superior colliculus. J Neurophysiol 49:1285-1301.

Hikosaka O, Wurtz RH (1985a) Modification of saccadic eye movements by GABA-related substances. I. Effect of muscimol and bicuculline in the monkey superior colliculus. J Neurophysiol 53:266291.

Hikusaka O, Wurtz RH (1985b) Modification of saccadic eye movements by GABA-related substances. II. Effects of muscimol in the monkey substantia nigra pars reticulata. J Neurophysiol 53:292-308.

Hikosaka O, Wurtz RH (1989) The basal ganglia. In: The neurobiology of saccadic eye movements (Wurtz RH, Goldberg ME, eds), pp 257281. Amsterdam: Elsevier

Hikosaka O, Igusa Y, Imai H (1978) Firing pattern of prepositus hypoglossi and adjacent reticular neurons related to vestibular nystagmus in the cat. Brain Res 144:395-403.

Hikosaka O, Sakamoto M, Usui S (1989) Functional properties of monkey caudate neurons. I. Activities related to saccadic eye movements. J Neurophysiol 61:780-798.

Hopkins DA, Niessen LW (1976) Substantia nigra projections to the reticular formation, superior colliculus and central gray in the rat, cat and monkey. Neurosci Lett 2:253-259.

Hotson JR, Langston EB, Langston JW (1986) Saccade responses to dopamine in human MPTP-induced parkinsonism. Ann Neurol 20: 456-463.

Huerta MF, Kaas JH (1990) Supplementary eye field as defined by intracortical microstimulation: connections in macaques. J Comp Neurol 293:299-330.

Huerta MF, Van Lieshout DP, Harting JK (1991) Nigrotectal projections in the primate Galago crassicaudatus. Exp Brain Res 87:389401.

Imai H, Nakamura T, Endo K, Narabayashi H (1988) Hemiparkinsonism in monkeys after unilateral caudate nucleus infusion of 1-methyl-4-phenyl-1,2,3,6-tetrahydropyridine (MPTP): behavior and histology. Brain Res 474:327-332.

Jayaraman A, Batton RR, Carpenter MB (1977) Nigrotectal projections in the monkey: an autoradiographic study. Brain Res 135:147152.

Kanazawa I, Marshall GR, Kelly JS (1976) Afferents to the rat substantia nigra studied with horseradish peroxidase, with special reference to fibres from the subthalamic nucleus. Brain Res 115:485491.

Kasdon DL, Jacobson S (1978) The thalamic afferents to the inferior parietal lobule of the rhesus monkey. J Comp Neurol 177:685-706.

Kato M, Usui S, Miyashita N, Matsumura M, Hikosaka O, Sakamoto M, Fukuda H, Imai H (1990) Hemiparkinsonism in monkeys. I. Changes in spontaneous eye movements. Jpn J Physiol [Suppl] 40: S206.

Kita H, Kitai ST (1987) Efferent projections of the subthalamic nucleus in the rat: light and electron microscopic analysis with the PHA-L method. J Comp Neurol 260:435-452.

Kita H, Chang HT, Kitai ST (1983) Pallidal inputs to subthalamus: intracellular analysis. Brain Res 264:255-265.

Kitai ST, Kocsis JD, Preston RJ, Sugimori M (1976) Monosynaptic inputs to caudate neurons identified by intracellular injection of horseradish peroxidase. Brain Res 109:601-606.

Kori A, Miyashita N, Kato M, Hikosaka O, Usui S, Matsumura M (1995) Eye movements in monkeys with local dopamine depletion in the caudate nucleus. II. Deficits in voluntary saccades. J Neurosci 15:928-941.

Langston JW (1985) MPTP and Parkinson's disease. Trends Neurosci 8:79-83.

Matsumura M, Kojima J, Gardiner TW, Hikosaka O (1992) Visual and oculomotor functions of monkey subthalamic nucleus. J Neurophysiol $67: 1615-1632$.

Mitchell IJ, Cross AJ, Sambrook MA, Crossman AR (1986) 1-Mcthyl4-phenyl-1,2,3,6-tetrahydropyridine-induced parkinsonism in the monkey: neurochemical pathology and regional brain metabolism. In: MPTP and the Aetiology of Parkinson's disease. Clinical implications (Parkes D, ed), pp 41-46. New York: Springer.

Mitchell IJ, Jackson A, Sambrook MA, Crossman AR (1989) The role of subthalamic nucleus in experimental chorea. Brain 112:1533-1548.

Miyashita N, Usui S, Kato M, Matsumura M, Hikosaka O, Sakamoto M, Fukuda H, Imai H (1990) Hemiparkinsonism in monkeys. II. Effects of a dopamine agonist on spontaneous eye movements. Jpn J Physiol [Suppl] 40:S206.

Parent A, Smith Y (1987) Organization of efferent projections of the subthalamic nucleus in the squirrel monkey as revealed by retrograde labeling methods. Brain Res 436:296-310.

Parent A, Smith Y, Arsenault M-Y (1987) Chemical anatomy of the basal ganglia in primates. In: The basal ganglia. II. Structure and function-current concepts (Carpenter MB, Jayaraman A, eds), pp 342. New York: Plenum.

Pifl C, Schingnitz G, Hornykiewicz O (1991) Effect of 1-methyl-4phenyl-1,2,3,6,-tetrahydropyridine on the regional distribution of brain monoamines in the rhesus monkey. Neuroscience 44:591-605. 
Robinson DA (1963) A method of measuring eye movement using a scleral search coil in a magnetic field. IEEE Trans Biomed Eng 10: 137-145.

Roll R, Velay JL, Roll JP (1991) Eye and neck proprioceptive messages contribute to the spatial coding of retinal input in visually oriented activities. Exp Brain Res 85:423-431.

Ruffieux A, Schultz W (1980) Dopaminergic activation of reticulata neurons in the substantia nigra. Nature 285:240-241.

Russchen FT, Amaral DG, Price JL (1987) The afferent input to the magnocellular division of the mediodorsal thalamic nucleus in the monkey, Macaca fascicularis. J Comp Neurol 256:175-210.

Schall JD (1991) Neuronal activity related to visually guided saccadic eye movements in the supplementary motor area of rhesus monkeys. J Neurophysiol 66:530-558.

Schlag J, Schlag-Rey M (1984) Visuomotor functions of central thalamus in monkey. II. unit activity related to visual events, targeting, and fixation. J Neurophysiol 51:1175-1195.

Schlag J, Schlag-Rey M, Pigarev I (1992) Supplementary eye field: influence of eye position on neural signals of fixation. Exp Brain Res 90:302-306.

Schneider JS, Kovelowski CJ II (1990) Chronic exposure to low doses of MPTP. I. Cognitive deficits in motor asymptomatic monkeys. Brain Res 519:122-128.

Schultz W, Ungerstedt U (1978) Short-term increase and long-term reversion of striatal cell activity after degeneration of the nigrostriatal dopamine system. Exp Brain Res 33:159-171.

Schultz W, Romo R, Scarnati E, Sundostrom E, Jonsson G, Studer A (1989a) Saccadic reaction times, eye-arm coordination and spontaneous eye movements in normal and MPTP-treated monkeys. Exp Brain Res 78:253-267.

Schultz W, Studer A, Romo R, Sundström E, Jonsson G, Scarnati E (1989b) Deficits in reaction times and movement times as correlates of hypokinesia in monkeys with MPTP-induced striatal dopamine depletion. J Neurophysiol 61:651-668.
Segraves MA (1992) Activity of monkey frontal eye field neurons projecting to oculomotor regions of the pons. J Neurophysiol 68 : 1967-1985.

Selby G (1968) In: Parkinson's discasc (Vinken PJ, Bruyn GW, eds), pp 173-211. Amsterdam: North Holland.

Sparks DL (1986) Translation of sensory signals into commands for control of saccadic eye movements: role of primate superior colliculus. Physiol Rev 66:118-171.

Sparks DL, Hartwich-Young R (1989) The deep layers of the superior colliculus. In: The neurobiology of saccadic eye movements (Wurtz RH, Goldberg ME, eds), pp 213-255. Amsterdam: Elsevier.

Szabo J (1962) Projections from the body of the caudate nucleus in the rhesus monkey. Exp Neurol 27:1-15.

Szabo J (1980) Organization of the ascending striatal afferents in monkeys. J Comp Neurol 189:307-321.

Ungerstedt U, Arbuthnott GW (1970) Quantitative recording of rotational behaviour in rats after 6-hydroxydopamine lesions of the nigro-striatal dopamine systcm. Brain Res 24:485-493.

Usui S, Fukuda H, Hikosaka O (1990) Spontaneous saccades in MPTPinduced hemi-parkinsonian monkeys. Clin Neurol 30:1181-1189.

Voneida TJ (1960) An experimental study of the course and destination of fibers arising in the head of caudate nucleus in the cat and monkey. J Comp Neurol 115:75-88.

Waszczak BL (1990) Differential effects of D1 and D2 dopamine receptor agonists on substantia nigra pars reticulata neurons. Brain Res 513:125-135.

Waszczak BL, Walters JR (1983) Dopamine modulation of the effects of $\gamma$-aminobutyric acid on substantia nigra pars reticulata neurons. Science 220:218-221.

Waszczak BL, Lee EK, Tamminga CA, Walters JR (1984) Effect of dopamine system activation on substantia nigra pars reticulata output neurons: variable single-unit responses in normal rats and inhibition in 6-hydroxydopamine-lesioned rats. J Neurosci 4:2369-2375. 